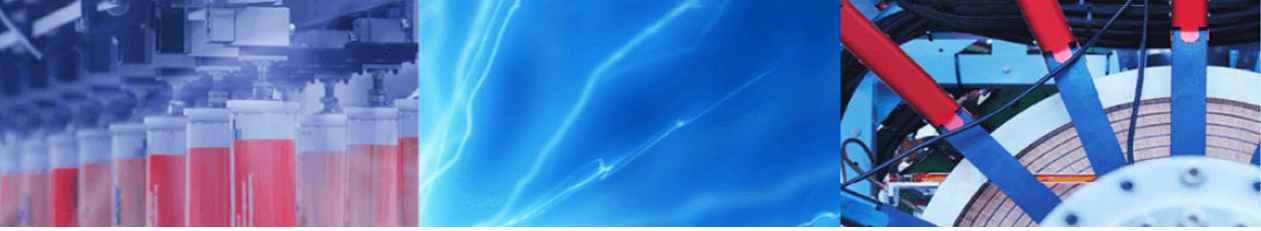

Research Article

\title{
A new extractant impregnated resin for separation of traces of uranium and thorium followed by their spectrophotometric determination in some geological samples
}

\author{
Hisham Fouad ${ }^{1}$. Saeyda Abu Elenein ${ }^{2} \cdot$ Ahmed Orabi $^{1} \cdot$ Shaimaa Abdulmoteleb ${ }^{1}$
}

() Springer Nature Switzerland AG 2019

\begin{abstract}
A new extractant-impregnated resin, alizarin red S-impregnated XAD-2010, is used as an adsorbent to separate and preconcentrate $\mathrm{U}(\mathrm{VI})$ and $\mathrm{Th}(\mathrm{IV})$ ions prior to their spectrophotometric determination. Various instrumental techniques such as elemental analysis, FTIR, and SEM analysis were employed for full characterization of the synthetic extractant. Optimization of the adsorption and elution conditions of $\mathrm{U}(\mathrm{VI})$ and $\mathrm{Th}(\mathrm{IV})$ ions using synthesized alizarin red $\mathrm{S}$-impregnated XAD-2010 were studied. Langmuir isotherm model has the best fitting experimental data with a maximum adsorption capacity of $20.2 \mathrm{mg} \mathrm{g}^{-1}$ for $\mathrm{U}(\mathrm{VI})$ and $18.25 \mathrm{mg} \mathrm{g}^{-1}$ for Th(IV). The adsorption process of each metal ion by synthesized alizarin red S -impregnated XAD-2010 showed an exothermic pseudo-second-order adsorption process. The tolerance limits for several metal ions on alizarin red S -impregnated XAD-2010 were calculated, giving high tolerance limit. The optimized method was applied on international certified samples and different rock types bearing thorium and uranium with accurate results.
\end{abstract}

Keywords Separation · Spectrophotometric · Uranium · Thorium · Alizarin red S -impregnated XAD-2010

\section{Introduction}

The twin important nuclear elements, thorium and uranium are the corner stone of the (industrial) nuclear technology and consequently the production of nuclear fuel used in nuclear power plants which has a return on the production of huge energy capable of developing any country due to its application as an efficient fuel for electric power plants [1, 2].

Accordingly, it is a strategic issue where their exploration in their bearing rocks and hence their exploitation for production of nuclear grade yellow cake (highly concentrated uranium) is an important step in the nuclear fuel cycle. So, their accurate determination using several advanced and single techniques with economic procedures will be of great prominence for a precise and accurate evaluation of their occurrences in certain areas $[3,4]$.
Several instrumental techniques were suggested namely; inductively coupled plasma atomic emission spectrometry and inductively coupled plasma mass spectrometry which can serve to improve sensitivity for uranium and thorium determination where, several trials are performed to reach economic and accurate methods for their determination [5].

Problems encountering the spectrophotometric technique in rock analysis are mainly referring to spectral interference which enhances the absorbance value giving out incorrect (high) concentration [6, 7].

To solve these problems, the segregation including coprecipitation, solvent extraction, electrodeposition, ionexchange etc. [8-10] has been used in the analytical chemistry laboratories for their precise and accurate determination. Solid phase extraction (SPE) is one of the efficient preconcentration-differentiation procedures used, due to

$\triangle$ Ahmed Orabi, a_orabi_chem@yahoo.com | ${ }^{1}$ Nuclear Materials Authority, P.O. Box 530, Maadi, Cairo, Egypt. ${ }^{2}$ Chemistry Department, Faculty of Science, Menofia University, Shibin El Kom, Egypt.

SN Applied Sciences (2019) 1:309 | https://doi.org/10.1007/s42452-019-0325-7

Received: 14 January 2019 / Accepted: 1 March 2019 / Published online: 6 March 2019 
its simplicity and confined usage of the organic solvents [11-15]. Solid phase extraction of thorium and uranium is also a preferable choice in the analytical chemistry in common [16-18]. Several properties of SPE such as selectivity, simplicity of equipment, ease of operation, and the multiple usages of adsorbents for numerous separation and preconcentration cycles without deprivation in the metal ion sorption capacity have made their use popular [19-24].

Amberlite $X A D$ resin folk are vital for solid phase extraction studies for heavy metal ions in the environmental samples $[25,26]$. These resins are extremely important from both, the economic and environmental point of views for solid phase extraction after their proper functionalization [27]. The literature survey revealed that XAD2000 and XAD-2010 are used for the preconcentration and seclusion of organic materials at trace levels; $[28,29]$ however, only few studies on these resins were highlighted for preconcentration of trace metals [30, 31].

Spectrophotometric method for determination (as a single cheap and available technique) using the proper sensitive and selective dye was merged with solid phase extraction technique for the solutions bearing the twin nuclear elements for a single, accurate, precise, and low cost technique for the precise determination of both elements was proposed in this work. In the pursuance of many researches on the extractant impregnated resins (EIRs) applications [21, 22, 32-37], this work converges on the eclectic separation and preconcentration of trace amounts of thorium and uranium in their bearing rocks using a new EIR containing Amberlite XAD-2010 resin beads impregnated with alizarin red $S$. The new EIR sorbent manifested eminent selectivity for thorium and uranium sorption from aqueous solutions after adequate optimization.

\section{Experimental}

\subsection{Reagents}

Alizarin red S (ARS) and Amberlite XAD-2010 were purchased from Sigma Chemicals. All the common reagents were supplied by VWR BDH Prolabo Chemicals (Fontenaysous-Bois, France). On the other hand, $\mathrm{U}(\mathrm{VI}), \mathrm{Th}(\mathrm{V}), \mathrm{Na}(\mathrm{I})$, $\mathrm{K}(\mathrm{I}), \mathrm{Ca}(\mathrm{II}), \mathrm{Mg}(\mathrm{II}), \mathrm{Al}(\mathrm{III}), \mathrm{Mn}(\mathrm{II}), \mathrm{Fe}(\mathrm{III}), \mathrm{Cr}(\mathrm{VI}), \mathrm{VO}(\mathrm{II}), \mathrm{Cu}(\mathrm{II})$, $\mathrm{Co}(\mathrm{III}), \mathrm{Ln}(\mathrm{III}), \mathrm{pb}(\mathrm{II}), \mathrm{Ba}(\mathrm{II}), \mathrm{Mo}(\mathrm{VI}), \mathrm{B}(\mathrm{III}), \mathrm{Cd}(\mathrm{II})$, and $\mathrm{Zn}$ (II) standard stock solutions, $1000 \mathrm{ppm}$, were analytical grade and purchased from Merck (Darmstadt, Germany).

\subsection{Preparation of the EIR}

The ARS-impregnated XAD-2010 resin beads were prepared using dry procedure [34]. Before the impregnation process, a pretreatment of amberlite XAD-2010 resin beads were handled with 1:1 methanol-water solution comprising $6 \mathrm{M}$ $\mathrm{HCl}$ for $12 \mathrm{~h}$ in order to drive out any enduring monomers and other species of impurities which may be found with the fabricated beads. The resin was totally rinsed with double-distilled water and placed into a drying oven at $323^{\circ} \mathrm{K}$ for $30 \mathrm{~min}$. To prepare the impregnated resin, portions of amberlite XAD-2010 resin ( $1 \mathrm{~g}$ of dry resin) were carried into a spectrum of glass stoppered bottles containing different concentrations of ARS in $200 \mathrm{~mL}$ methanol, which was utilized as the solvent. The entire contents were slowly shaken for $10 \mathrm{~h}$ to accomplish impregnation process and then were heated at $333^{\circ} \mathrm{K}$ in a drying oven to drive out the solvent. Each EIR sample was then conveyed to a porous filter and washed consecutively with $\mathrm{HCl}(3 \mathrm{M})$ solution and enormous amounts of distilled water until no ARS was found in the filtrate. Eventually, the impregnated resins were dried at $323^{\circ} \mathrm{K}$ and weighed. Compound structure was characterized by means of SEM using a Jeol (Tokyo, Japan) JSM 5600 LV scanning electron microscope, FTIR spectrometer Bruker Vector 22 Germany in the range of $400-4000 \mathrm{~cm}^{-1}$, and elemental analysis.

\subsection{Analytical procedures}

$\mathrm{U}$ and Th were spectrophotometerically determined by using the chromogenic reagent, Arsenazo-III and thoron I, respectively [38]. Other interfering elements were analyzed using ICP-OES, Teledyne technologies (Inductively Coupled Plasma Optical Emission Spectrometer).

\subsection{Statistical and accuracy evaluation}

Statistical techniques are applied, in the present work, in two ways: one of them is for estimating precision and accuracy of the analytical data and the second is for quality assurance of the produced concentrate. A common practice in analytical chemistry literature is to quote the mean $(\bar{X})$ as a common factor for estimating the precession (degree of reproducibility or random error). Accuracy $(\Delta)$ of a measurement method is defined as the measure of the closeness of results to reference (well known) or true one. The following equations are therefore applied [39-41]:

Arithmetic mean: $\bar{X}=\frac{\sum X_{i}}{n}$

where $\mathrm{X} i$, individual measurement; $\mathrm{n}$, number of measurements.

Standard deviation: $S D=\left[\frac{\sum_{1}^{n}\left(X_{i}-\bar{X}\right)^{2}}{(n-1)}\right]^{1 / 2}$

\section{SN Applied Sciences}


Relative standard deviation: $R S D=S D / \bar{X} \times 100$

Standard error: $S E=\frac{S D}{\sqrt{n}}$

The percentage error: \%Error $=S E / \bar{X} \times 100$

Accuracy: $\Delta= \pm \sqrt{\frac{d^{2}}{2 n}}$

where $d$ represents the difference between the repeated measurements.

\subsection{Adsorption procedure}

In the adsorption process, a batch technique was used to study different parameters affecting uranium and thorium adsorption process for the prepared EIR in all experiments such as $\mathrm{pH}$, contact time, initial metal concentration, temperature and interfering ions. Thus, a sample $(\mathrm{S})$ weight of $0.1 \mathrm{~g}(\mathrm{~m})$ was added to a volume of $50 \mathrm{~mL}(V)$ of $U$ or Th aqueous solutions and equilibrated by stirring at room temperature. After a certain time, the solutions were filtrated and the concentration of uranium and thorium was spectrophotometrically determined. Both the determination of the adsorption coefficient (Ads \%) and the adsorption capacity (q) were calculated using the following equations:

$q=\left(\frac{\left(C_{i}-C_{f}\right)}{m}\right) \times V$
Ads $\%=\left(\frac{\left(C_{i}-C_{f}\right)}{C i}\right) \times 100$

where $C_{i}$ and $C_{f}$ are the initial and the final concentrations of aqueous phases, respectively.

\section{Results and discussion}

\subsection{Preparation of ARS-impregnated resin}

Alizarin Red S dye (ARS) contains two hydroxyl groups and sulphonate group, making it suitable for chelate formation with several metal ions. It is easily soluble in alcohol or water, and changes its colour with $\mathrm{pH}$ (yellow at $\mathrm{pH}<4$, orange to intense red in the $\mathrm{pH}$ region 4-8, and violet at $\mathrm{pH}>9$ ). Alizarin Red $\mathrm{S}$-impregnated XAD2010, ARS/XAD-2010, was efficiently prepared by the impregnation method, described in the experimental section. To prepare the suitable form of ARS/XAD-2010, various impregnation ratios; g ARS/g dry XAD-2010 adsorbent were studied and the data was illustrated in Fig. 1. As shown, the weight change (\%) increases as the impregnation ratio increases after which a plateau is reached at the impregnation ratio of $1.5 \mathrm{~g} \mathrm{ARS} / \mathrm{g}$ dry XAD-2010 adsorbent, where it was adopted as the optimum impregnation ratio.
Fig. 1 Effect of the impregnation ratio on the EIR preparation at the condition that portions of $1-\mathrm{g}$ of the dry polymer beads of Amberlite XAD-2010 was subjected to the impregnation process

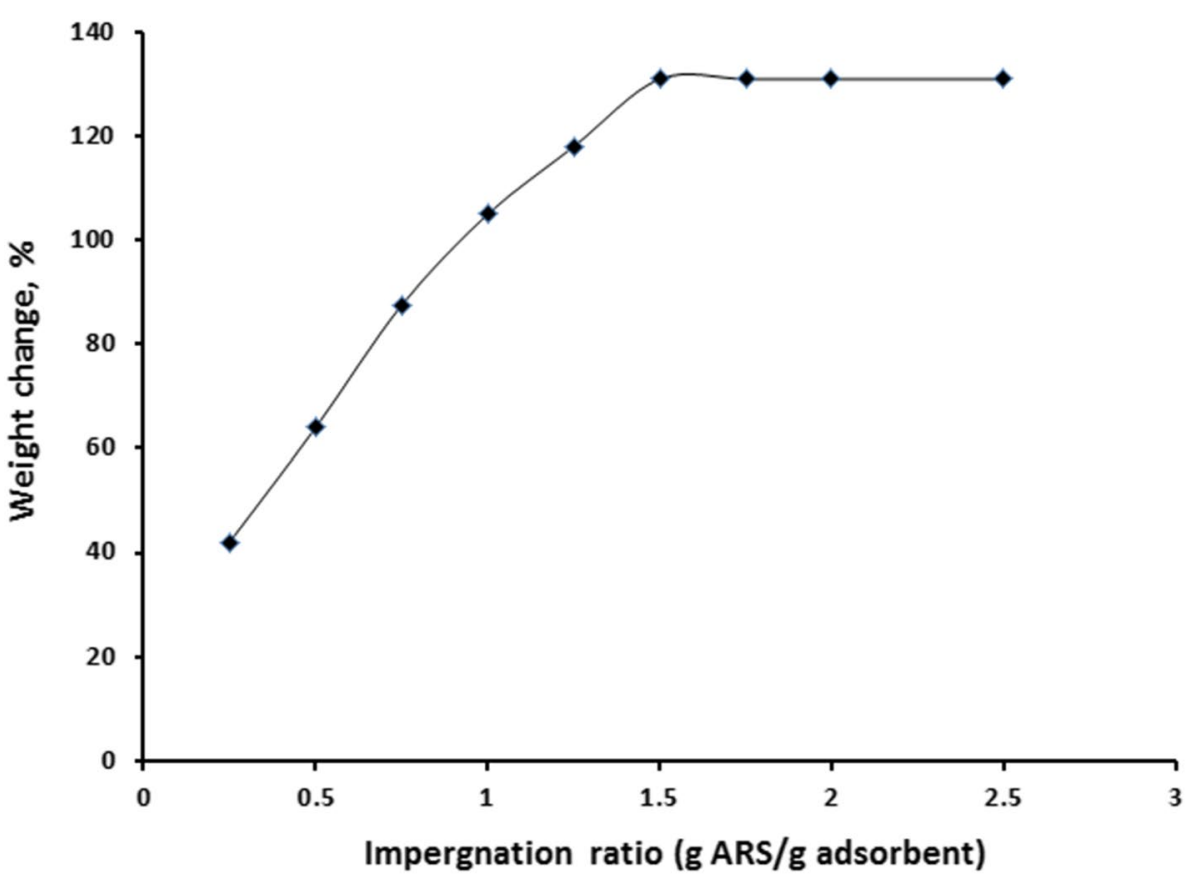

SN Applied Sciences 


\subsection{Stabilizing extractant capacity impregnated on the polymer}

The immobilization of the extractant on the macroporous matrices during the impregnation process is invaded in pores (due to the capillary forces) and in the gel regions of the polymer beads. The impregnated extractant located in pores is weakly bonded and represents the unstable part of EIR capacity; thus, it can be easily leached out from the freshly prepared EIR sample. Otherwise, the most stable part and remains constant that is taken up by the gel regions of the macroporous matrix [42, 43]. According to Hosseini-Bandegharaei et al. [44], the chemical stability of the Extractant Impregnating Resin (ARS/XAD-2010) was examined by sequentially suspending a $0.1 \mathrm{~g}$ of EIR in different $\mathrm{pH}$ values and shaking for $10 \mathrm{~h}$. The new EIR was filtered and rinsed with double distilled water; the resulted solution was clear. The released amount of ARS was examined by weighing the EIR (ARS/XAD-2010). It was found that no change in its quantity indicates a high stability.

\subsection{Characterization of the modified resin}

In order to verify the presence of the active functional groups of ARS in the modified resin, IR spectra of Amberlite XAD-2010 and the ARS/XAD-2010 modified resin were obtained (Fig. 2). The IR spectrum of amberlite XAD 2010 resin exhibited less intense band at $3436 \mathrm{~cm}^{-1}$, which can be attributed to the stretching vibrations of adsorbed water [45]. The bands at 2924 and $1632 \mathrm{~cm}^{-1}$ are assigned to the aliphatic $-\mathrm{CH}_{2}-\mathrm{CH}_{2}$ chains and the phenyl rings, respectively [46-49].

Upon modification with ARS, the phenolic-OH band appears at $3432 \mathrm{~cm}^{-1}[46,50]$. The most noticeable change in the spectra is the band at 1266 and $1159 \mathrm{~cm}^{-1}$ which are due to the stretching $\mathrm{SO}_{3}{ }^{2-}$ and $\mathrm{C}-\mathrm{S}$ band at $585 \mathrm{~cm}^{-1}[46,51]$. The band at $1022 \mathrm{~cm}^{-1}$ is assigned to the stretching vibration of $\mathrm{S}=\mathrm{O}$ group. Moreover the bands were assigned to $\mathrm{C}-\mathrm{O}$ at 1061 and $1105 \mathrm{~cm}^{-1}$ and the $\mathrm{C}=\mathrm{O}$ band at $1635 \mathrm{~cm}^{-1}[46,48,49,51-53]$. The above mentioned bands indicate the modification of amberlite XAD 2010 with ARS.

The CHNS elemental analysis of Amberlite XAD-2010 and the ARS/XAD-2010 modified resin were obtained (Table 1). The elemental analysis of the ARS/XAD-2010 was conducted with an erratic increase in the $\mathrm{C}, \mathrm{H}$ and $\mathrm{N}$ contents than Amberlite XAD-2010. In addition, the presence of $S$ element (3.15\%) confirms the impregnation of ARS into Amberlite XAD-2010 as shown in Table 1.

Table 1 The CHNS elemental analysis of Amberlite XAD-2010 and the ARS/XAD-2010 modified resin

\begin{tabular}{lllll}
\hline Sample & $\mathrm{C}$ & $\mathrm{H}$ & $\mathrm{N}$ & $\mathrm{S}$ \\
\hline Amberlite XAD-2010 & 39.12 & 5.03 & 3.26 & - \\
ARS/XAD-2010 modified resin & 64.63 & 6.45 & 3.73 & 3.15 \\
\hline
\end{tabular}

Fig. 2 FTIR spectroscopy of the working polymeric resin: (A) Amberlite XAD-2010 and (B) ARS/XAD-2010 modified resin

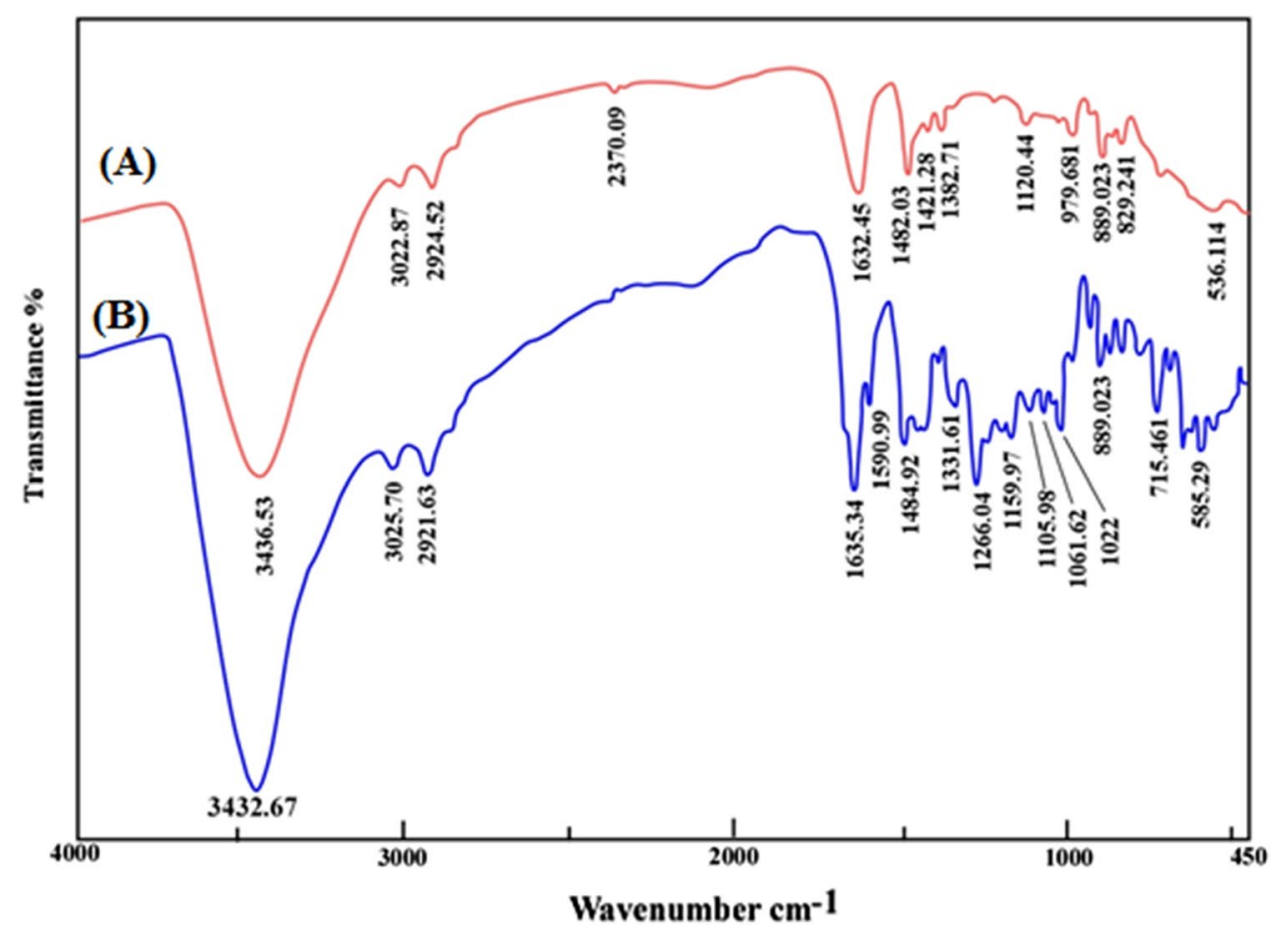




\subsection{Effect of acid medium}

From the critical parameters for solid phase extraction of metal ions is the type of acidic medium. The effect of perchloric acid, hydrochloric acid, nitric acid and sulfuric acid on sorption process and complex formation between metal ions and synthesized EIR were studied. For this purpose, $50 \mathrm{~mL}$ aliquots of $\mathrm{U}(\mathrm{VI})$ and Th(IV) solutions ( $\mathrm{pH}$ 3) having concentration of $500 \mathrm{\mu g} \mathrm{L}^{-1}$ in different acid concentrations were treated with $0.1 \mathrm{~g}$ portions of EIR at $298 \pm 1 \mathrm{~K}$. As shown in Table 2, the adsorption of metal ions on synthesized EIR with perchloric acid gives the highest adsorption percentages. As expected, increasing acid concentration leads to enhance the salt effect and consequently, the adsorption process is encountered with some restriction. Also, the crystals of salt occupy the superficial area of the EIR at high salt concentrations, which diminish the EIR available to interact with the analytes and play a very negative role by decreasing the recovery. The same behavior agrees with that reported earlier using other adsorbents [22, $44,54,55]$. Perchloric acid was selected for optimum adsorption experiments.

\subsection{Effect of pH}

As mentioned above, the synthesized EIR (ARS/XAD-2010) can take up uranium and thorium in high yield from aqueous perchloric acid solutions containing uranium and thorium. A glance at the extractant structure shows the presence of different donating atoms or functional groups such as $\mathrm{OH}, \mathrm{C}=\mathrm{O}$, and S-donor ligands which readily form complexes with uranium and thorium ions. The $\mathrm{pH}$ extensively affects the metals ion accumulation on the sorbent and their chelate formation. The effect of $\mathrm{pH}$ on the adsorption process was investigated in the range of 1-5 under the above optimum conditions (Fig. 3).

It was found that the adsorption of uranium was very low at perchloric solution $(0.01 \mathrm{M})$ with lower $\mathrm{pH}$ value but, thorium can be adsorbed effectively with $98 \%$ yield and then declines slowly to $20 \%$ solution at $\mathrm{pH} 5$ by synthesized EIR (ARS/XAD-2010) due to the formation of thorium hydroxide precipitate species after $\mathrm{pH} 3.5[56,57]$. On the other hand, uranium gives high yield of adsorption at $\mathrm{pH} 4$ and begins to decrease above $\mathrm{pH} 4.5$, due to the formation of colloidal and oligomeric species that can precipitate uranium as hydroxides in the solution or at the surface of the sorbent [56-59]. The result agreed with that reported earlier using other adsorbents $[22,54$, 55]. Lower adsorption of each analyte at $\mathrm{pH}$ values lower
Table 2 The effect of different acid concentrations of several acidic media

\begin{tabular}{|c|c|c|c|c|c|c|c|c|}
\hline \multirow[t]{2}{*}{ Acid conc. } & \multicolumn{4}{|c|}{ Th adsorption (\%) } & \multicolumn{4}{|c|}{ U adsorption (\%) } \\
\hline & $\mathrm{HClO}_{4}$ & $\mathrm{HNO}_{3}$ & $\mathrm{HCl}$ & $\mathrm{H}_{2} \mathrm{SO}_{4}$ & $\mathrm{HClO}_{4}$ & $\mathrm{HNO}_{3}$ & $\mathrm{HCl}$ & $\mathrm{H}_{2} \mathrm{SO}_{4}$ \\
\hline 0.01 & 75.0 & 62.5 & 70.0 & 50.0 & 78.0 & 60.0 & 66.0 & 54.0 \\
\hline 0.025 & 70.0 & 54.0 & 56.0 & 40.7 & 66.0 & 50.0 & 52.0 & 43.0 \\
\hline 0.05 & 50.0 & 43.0 & 43.2 & 30.4 & 48.2 & 40.0 & 45.8 & 32.3 \\
\hline 0.10 & 42.0 & 31.4 & 33.5 & 25.6 & 38.2 & 31.6 & 36.8 & 24.8 \\
\hline
\end{tabular}

Fig. 3 Effect of $\mathrm{pH}$ on the adsorption efficiency percent of uranium and thorium using $50 \mathrm{~mL}$ of solution of $0.5 \mathrm{mg} \mathrm{L}^{-1}$ with respect to $\mathrm{U}(\mathrm{VI})$ and $\mathrm{Th}(\mathrm{IV})$ ions and 10 min contact time

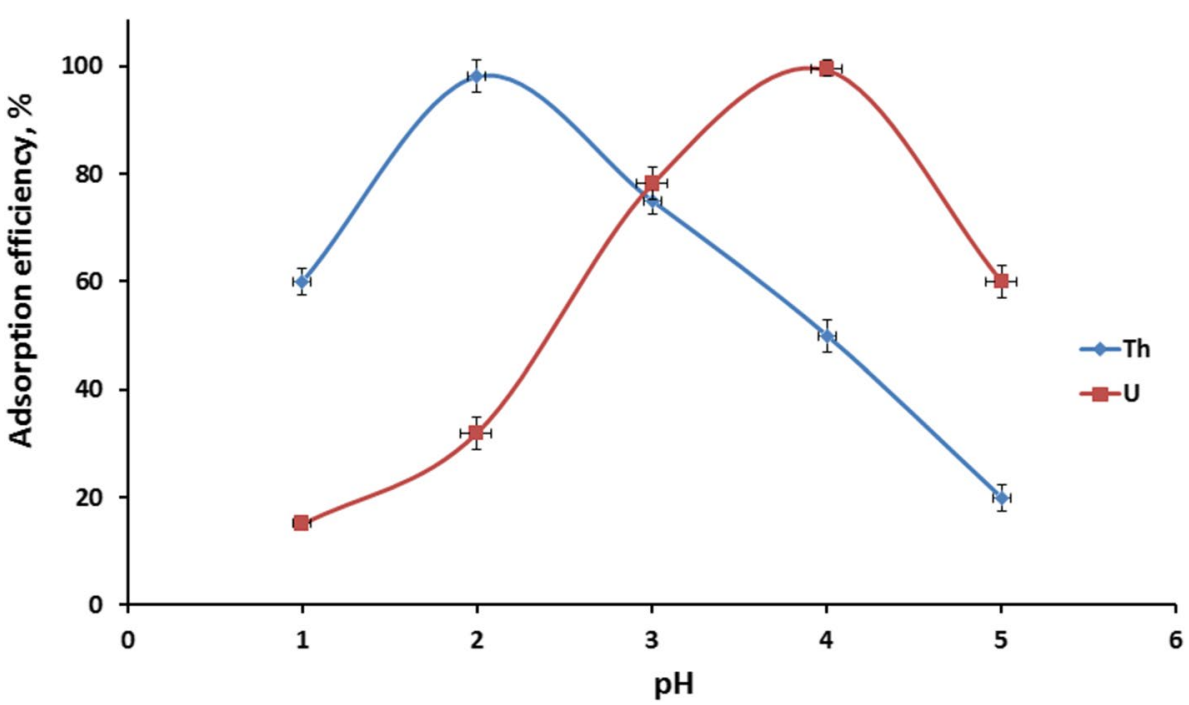

SN Applied Sciences 
than the optimum values can be due to (1) the rivalry of $\mathrm{H}^{+}$with analyte ions for special functional groups, which are responsible for complexation of each analyte to ARS/ XAD-2010, (2) partial protonation of the functional groups of extractant molecules. So, the adsorption of the analyte thorium ion was quite high and comparable suggesting marginal or no interference from uranium at lower $\mathrm{pH}$ (2). As a result of the above, the authors suggested separation of thorium firstly by the synthesized EIR (ARS/XAD-2010) from perchloric solution then effluent was subjected to uranium adsorption with a high yield of selectivity.

\subsection{Effect of contact time and kinetic studies}

Kinetic behavior of uranium and thorium adsorption from $0.01 \mathrm{M}$ perchloric acid solution using the synthetic sorbent, in terms of adsorbed amount $\mathrm{q}_{\mathrm{t}}\left(\mathrm{mg} \mathrm{g}^{-1}\right)$, is illustrated in Fig. 4. The adsorption into synthesized EIR (ARS/ XAD-2010) is passed through two stages:, the first stage where adsorption increased rapidly up to 5 min which is attributed to more available sites of EIR for adsorption, and finally equilibrium stage has been attained at $10 \mathrm{~min}$ (Fig. 4) referred to all the sites present on adsorbent get satisfied $[60,61]$. It can be seen that over $75 \%$ of uranium and thorium adsorption efficiency achieved within the first $3 \mathrm{~min}$. In addition, equilibrium adsorption (99.2\% for $U$ and $98 \%$ for Th) occurred within $10 \mathrm{~min}$.

The experimental data was treated with various kinetic models including the pseudo-first order and the pseudosecond order for evaluating the kinetic mechanism of adsorption process.

The equations of pseudo-first-order and pseudo-second-order models are specified as follows $[62,63]$ : $\log \left(q_{e}-q_{t}\right)=\log q_{e}-\frac{k_{1} t}{2.303}$

$\frac{t}{q_{t}}=\frac{1}{k_{2} q_{e}^{2}}+\frac{t}{q_{e}}$

where $q_{e}$ and $q_{t}\left(\mathrm{mg} \mathrm{g}^{-1}\right)$ are the capacities of each analyte adsorption by synthesized EIR at equilibrium and time $\mathrm{t}$ respectively. $k_{1}(1 / \mathrm{min})$ and $k_{2}\left(\mathrm{~g} \mathrm{mg}^{-1} \mathrm{~min}^{-1}\right)$ is pseudo first-order and second order sorption rate constants respectively. The values of constants $\left(\mathrm{q}_{\mathrm{e}}, \mathrm{k}_{1}\right.$, and $\left.\mathrm{K}_{2}\right)$ were calculated from the lines (Fig. 5) and given in Table 3. Consequently, Pseudo second order model has better fitting experimental data performance in terms of higher correlation coefficient and conformity with equilibrium adsorbed amount qe.

The intra-particle diffusion model is expressed as [64, 65]:

$\mathrm{q}_{\mathrm{t}}=\mathrm{k}_{\mathrm{id}} \mathrm{t}^{0.5}+\mathrm{C}$

where $\mathrm{q}_{\mathrm{t}}\left(\mathrm{mg} \mathrm{g}^{-1}\right)$ is the metal adsorbed amount at time $\mathrm{t}, \mathrm{K}_{\mathrm{id}}\left(\mathrm{mg} \mathrm{g}^{-1} \mathrm{~min}^{0.5}\right)$ is the intraparticle diffusion rate constant and $C$ is the thickness of the boundary layer.

The intraparticle diffusion parameters are calculated from the slope and the intercept of the linear plots as expressed in Fig. 6 . The plots of $q_{t}$ versus $t^{0.5}$ show that the obtained straight lines do not pass through the origin $(C>0)$. The obtained data in Table 3 is found that the values of correlation coefficient $R^{2}$ are 0.94 and 0.96 for Th and $U$ respectively. The obtained data confirm that this model is not appropriate for describing the sorption kinetics. Finally, from the kinetic parameters of three kinetic models as seen in Table 3, the adsorption kinetics
Fig. 4 Effect of time upon uranium and thorium adsorption efficiency from $50 \mathrm{~mL}$ $0.01 \mathrm{M}$ perchlorate medium ( $\left(500 \mu \mathrm{g} \mathrm{L}^{-1}\right.$ of each $\mathrm{U}$ and Th) by $0.1 \mathrm{~g}$ synthesized EIR at $25^{\circ} \mathrm{C}$

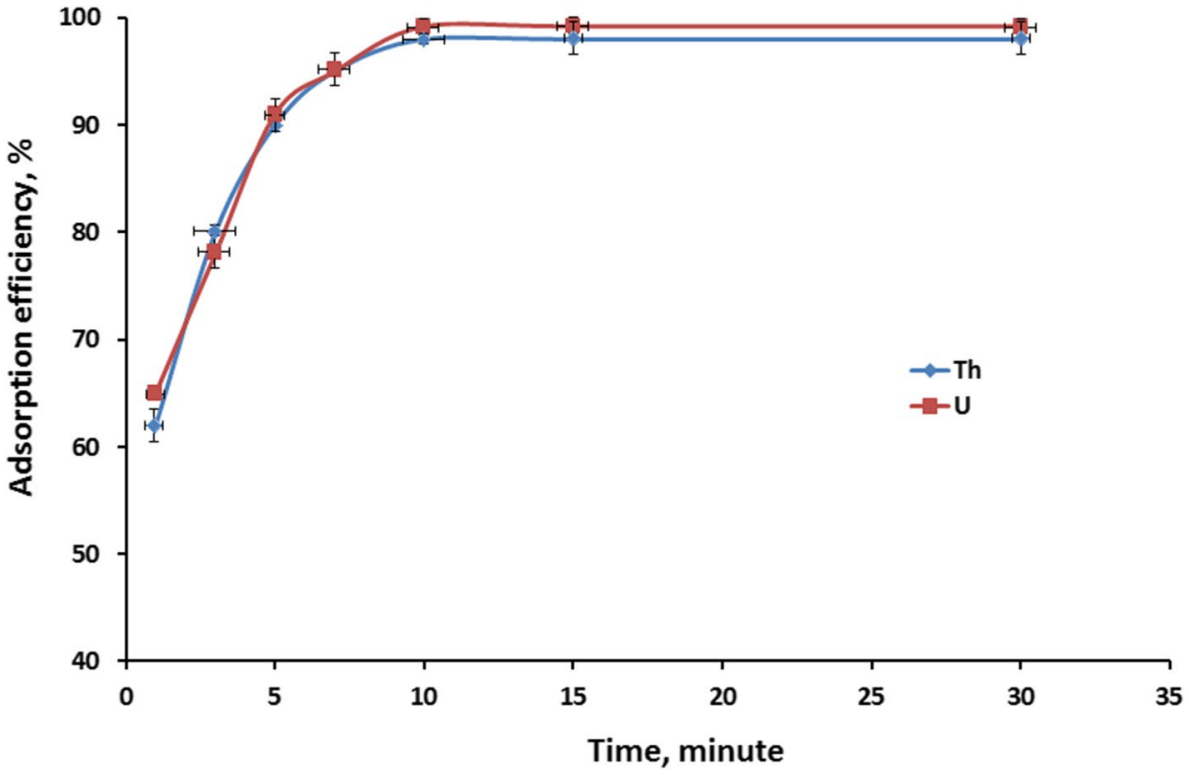



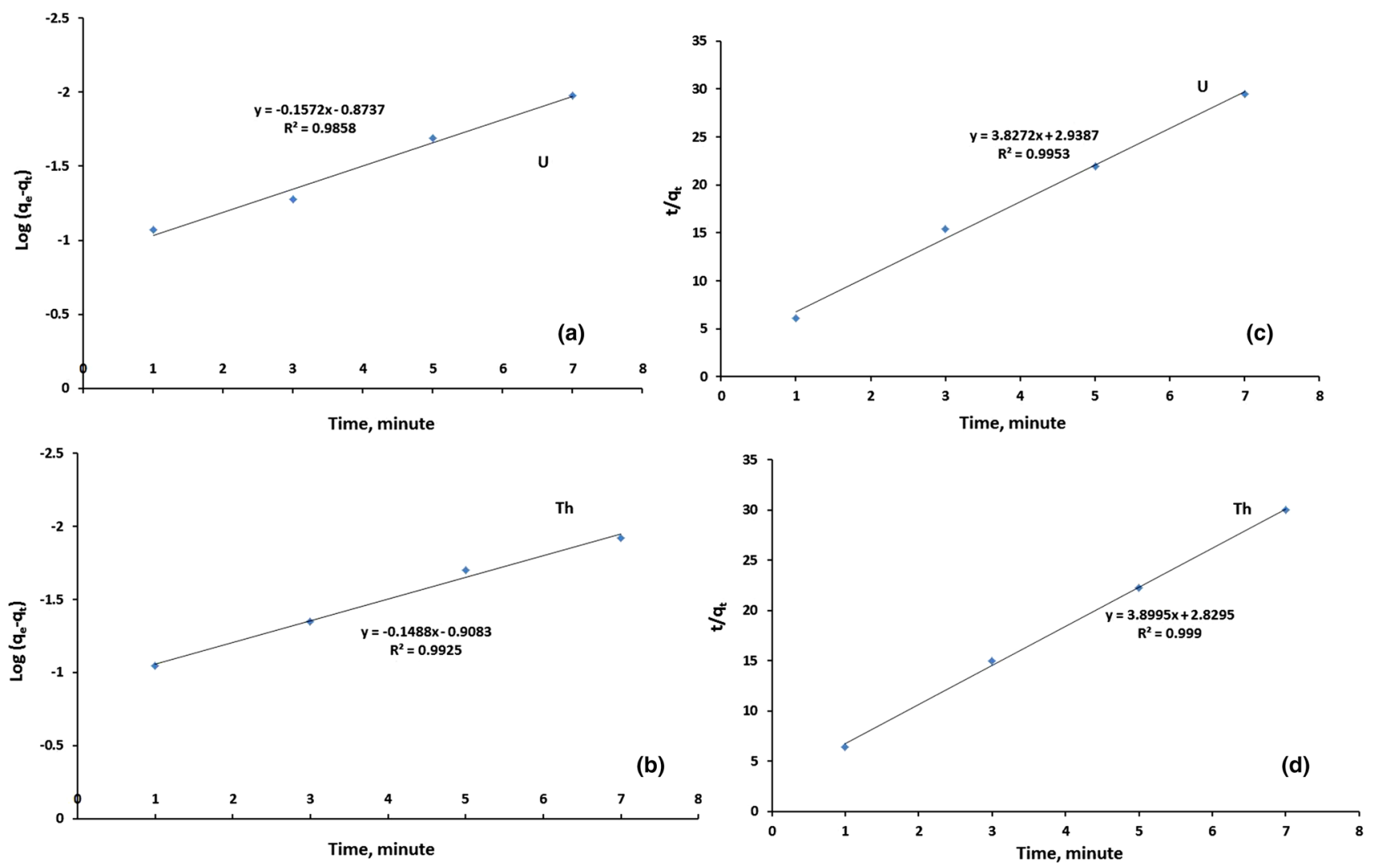

Fig. 5 Pseudo-first-order $(\mathbf{a}, \mathbf{b})$ and pseudo-second (c, $\mathbf{d})$ kinetics of $U$ and Th adsorption by synthesized EIR from the synthetic perchloric acid ( $0.01 \mathrm{M} \mathrm{HCLO}_{4}$ and $0.5 \mathrm{mg} \mathrm{L}^{-1}$ of each $\mathrm{U}$ and Th) at $25^{\circ} \mathrm{C}$

Table 3 Kinetic parameters for the adsorption of U(VI) and Th(IV) ions onto synthesized EIR (ARS/XAD-2010)

\begin{tabular}{|c|c|c|c|c|c|c|c|c|c|c|}
\hline \multirow[t]{2}{*}{ Metal ions } & \multirow[t]{2}{*}{ Exp. $q_{\mathrm{e}}\left(\mathrm{mg} \mathrm{g}^{-1}\right)$} & \multicolumn{3}{|c|}{ Pseudo-First-order } & \multicolumn{3}{|c|}{ Pseudo-Second-order } & \multicolumn{3}{|c|}{ Intraparticle diffusion } \\
\hline & & $q_{\mathrm{e}}\left(\mathrm{mg} \mathrm{g}^{-1}\right)$ & $K_{1}\left(\min ^{-1}\right)$ & $R^{2}$ & $q_{\mathrm{e}}\left(\mathrm{mg} \mathrm{g}^{-1}\right)$ & $\begin{array}{l}K_{2} \\
\left(\mathrm{~g} \mathrm{mg}^{-1} \mathrm{~min}^{-1}\right)\end{array}$ & $R^{2}$ & $\begin{array}{l}k_{i d} \\
\left(\mathrm{mg} \mathrm{g}^{-1} \min ^{-1 / 2}\right)\end{array}$ & $C\left(\mathrm{mg} \mathrm{g}^{-1}\right)$ & $R^{2}$ \\
\hline $\mathrm{U}(\mathrm{VI})$ & 0.248 & 0.134 & 0.362 & 0.985 & 0.261 & 5.00 & 0.995 & 0.0402 & 0.1219 & 0.96 \\
\hline Th(IV) & 0.245 & 0.124 & 0.343 & 0.992 & 0.256 & 5.37 & 0.999 & 0.0416 & 0.1266 & 0.94 \\
\hline
\end{tabular}

is estimated and fitted well by the pseudosecond-order kinetic model.

\subsection{Effect of initial $U$ and Th concentration and the adsorption mechanism}

Based on mixing a series of batch experiments at ambient temperature $\left(\approx 25^{\circ} \mathrm{C}\right)$, it can be concluded that the adsorbed uranium and thorium increases with increasing the initial uranium and thorium concentrations in solution till the saturation plateau. The maximum uranium and thorium sorption capacity was acquired by conducting a fixed EIR (ARS/XAD-2010) weight $(0.1 \mathrm{~g})$ with $50 \mathrm{~mL}$ of $U$ and Th at different concentrations in perchloric acid $(0.01 \mathrm{M})$, and at optimum conditions for each metal ion.
From Fig. 7, we can conclude that the maximum adsorption capacity of uranium and thorium from perchloric acid by EIR (ARS/XAD-2010) was $19 \mathrm{mg} \mathrm{U} \mathrm{g}^{-1}$ EIR and $17 \mathrm{mg}$ Th $\mathrm{g}^{-1}$ EIR. It is interesting to compare the achieved $\mathrm{U}(\mathrm{VI})$ and Th(IV) adsorption capacities on the synthesized EIR with other previously prepared sorbents. It was found that the synthesized EIR is competitive when compared with other previously prepared sorbents such as Mannich type resin (qmax: $5.2 \mathrm{mg} \mathrm{U} \mathrm{g}^{-1}$ and $2.28 \mathrm{mg} \mathrm{Th} \mathrm{g}^{-1}$ [57]), modified benzophenone (qmax: $2.42 \mathrm{mg} \mathrm{U} \mathrm{g}^{-1}$ [66] and $1.1 \mathrm{mg} \mathrm{Th}^{-1}$ [67]), Carminic acid (CA) impregnated XAD16 (1.93 $\mathrm{mg} \mathrm{U} \mathrm{g}^{-1}$ and $1.92 \mathrm{mg} \mathrm{Th}^{-1}$ [22]), Quinoline-8-ol impregnated XAD-4 (qmax: $2.74 \mathrm{mg} \mathrm{U} \mathrm{g}^{-1}$ [68]), o-Vaniline semicarbazone impregnated XAD-4 (qmax: $2.89 \mathrm{U} \mathrm{g}^{-1}$ [69], Pyrogallol impregnated XAD-2 (qmax: $6.71 \mathrm{mg} \mathrm{U} \mathrm{g}^{-1}$ [70]), 
Fig. 6 Intra-particle diffusion model of Th(IV) (a) and U(VI) (b) adsorption by $0.1 \mathrm{~g}$ synthesized EIR from $50 \mathrm{~mL} 0.01 \mathrm{M}$ perchloric acid $\left(500 \mu \mathrm{g} \mathrm{L}^{-1}\right.$ of each $\mathrm{U}$ and $\mathrm{Th}$ ) at $25^{\circ} \mathrm{C}$

Fig. 7 Effect of initial uranium and thorium concentrations on adsorption efficiency of synthesized EIR from perchlorate medium (adsorption condition: $50 \mathrm{~mL}$ of solution of $0.01 \mathrm{M}$ perchloric acid and 10 min contact time at room temperature)
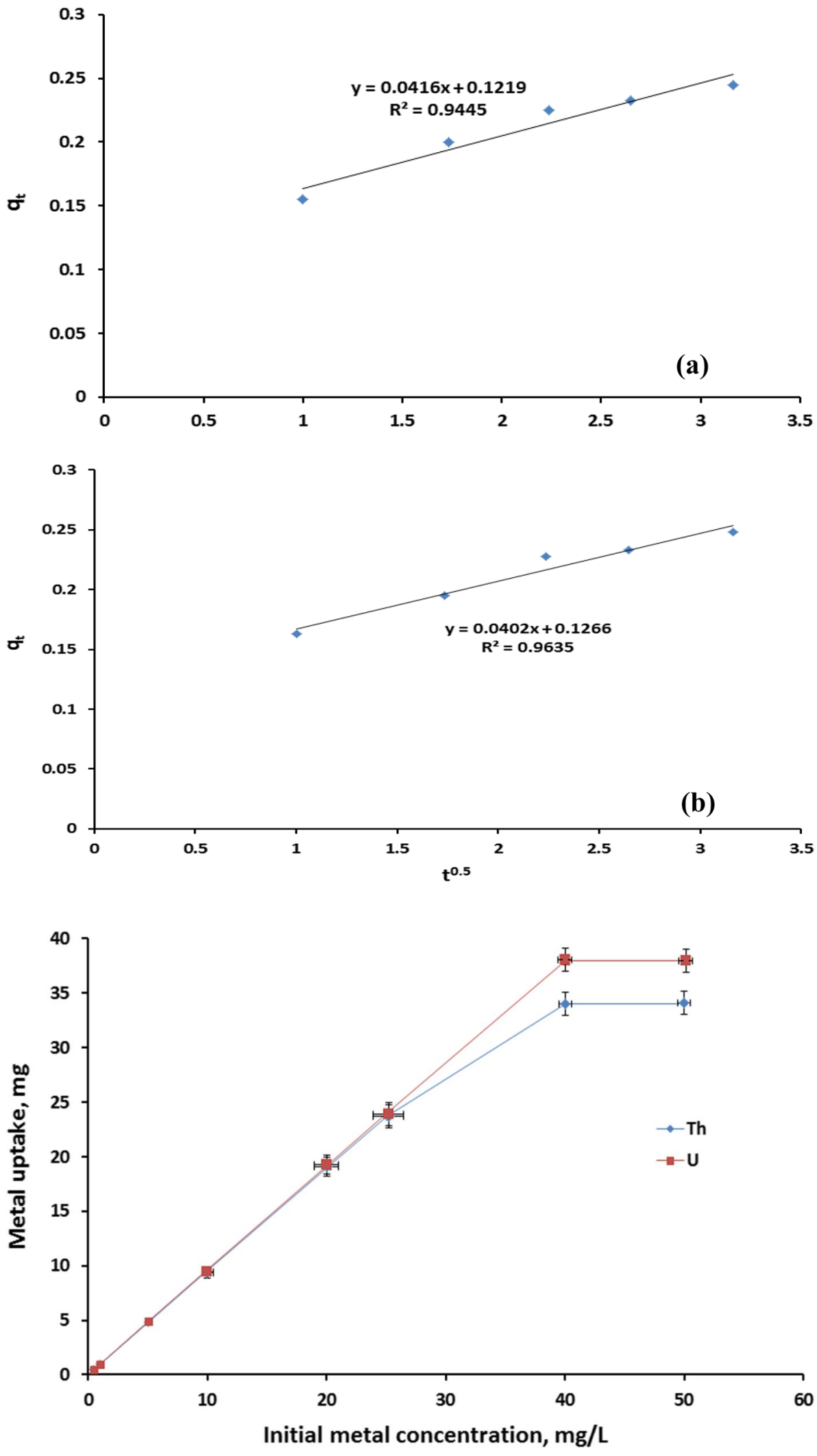
modified naphthalene (qmax: $1.88 \mathrm{mg} \mathrm{U} \mathrm{g}^{-1}$ [20]), modified silica (qmax: $3.02 \mathrm{mg} \mathrm{U} \mathrm{g}^{-1}[71]$ ), Tiron impregnated XAD-2 (qmax: $7.70 \mathrm{mg} \mathrm{U} \mathrm{g}^{-1}$ [72]), and [(2-dihydroxyarsinoylphenylamino) methyl] phosphonic acid functionalized XAD-16 (3.55 $\mathrm{mg} \mathrm{U} \mathrm{g}^{-1}$ and $3.25 \mathrm{mg} \mathrm{Th} \mathrm{g}^{-1}$ [73]).

The infrared technique was used for further study of the adsorption mechanism (Fig. 8). Comparing both spectra of EIR before and after adsorption, it can be observed that the main difference between absence of thorium and uranium ions (Fig. 2B) and their complexation with synthesized resin (Fig. 8A, B) was some band shifts which were observed due to interaction with $U$ and Th. The band belonging to $\mathrm{C}=\mathrm{O}$ unit of synthesized resin shifted to $1637 \mathrm{~cm}^{-1}$. Also, the IR spectrum of the modified resin loaded with uranium and thorium is also characterized by the shift of $\mathrm{C}-\mathrm{O}$ bands to $1234,1188,1161$, and $1090 \mathrm{~cm}^{-1}$. The band of $\mathrm{OH}$ becomes weak and less intense due to the interaction with $U$ and Th ions. As a result, we can say that the ketonic and phenolic groups are coordinated to the $U$ and $T h$ ions and the result agreed with that reported earlier $[22,46,50,74,75]$ which indicate that sorption of uranium and thorium takes place through complexation with ARS loaded on the resin and that amberlite XAD 2010 is applied only as an immobilization substrate for ARS reagent.
From the SEM images of the ARS/XAD-2010 synthesized resin before and after uranium(VI) and thorium(IV) adsorption are shown in Fig. 9a-c, respectively. The SEM images show the observation of brilliant spots on the resin beads variation after $\mathrm{U}(\mathrm{VI})$ and $\mathrm{Th}(\mathrm{IV})$ adsorption other than that uniformity and smooth surface of ARS/XAD-2010 synthesized resin.

As could be seen from the results, a visible change of the surface morphology in the $\mathrm{U}(\mathrm{VI})$ and Th(IV) adsorbed resin demonstrates that the sorption of studied metal ions take place onto the ARS/XAD-2010 synthesized resin.

\subsection{Isotherm studies}

In order to describe and understand the adsorption properties of uranium and thorium from $0.01 \mathrm{M}$ perchloric acid towards synthesized EIR, Langmuir and Freundlich models were established to fit the experimental data. The equation of Langmuir (12) and Freundlich (13) models are specified as follows [76]:

$\frac{C_{e}}{q_{e}}=\frac{C_{e}}{q_{\max }}+\frac{1}{K_{L} q_{\max }}$

$\log q_{\mathrm{e}}=\log K_{\mathrm{f}}+\frac{\log C_{\mathrm{e}}}{n}$
Fig. 8 FTIR spectroscopy of Th-loaded synthesized (ARS/ XAD-2010) (A) and U-loaded synthesized (ARS/XAD-2010) (B)

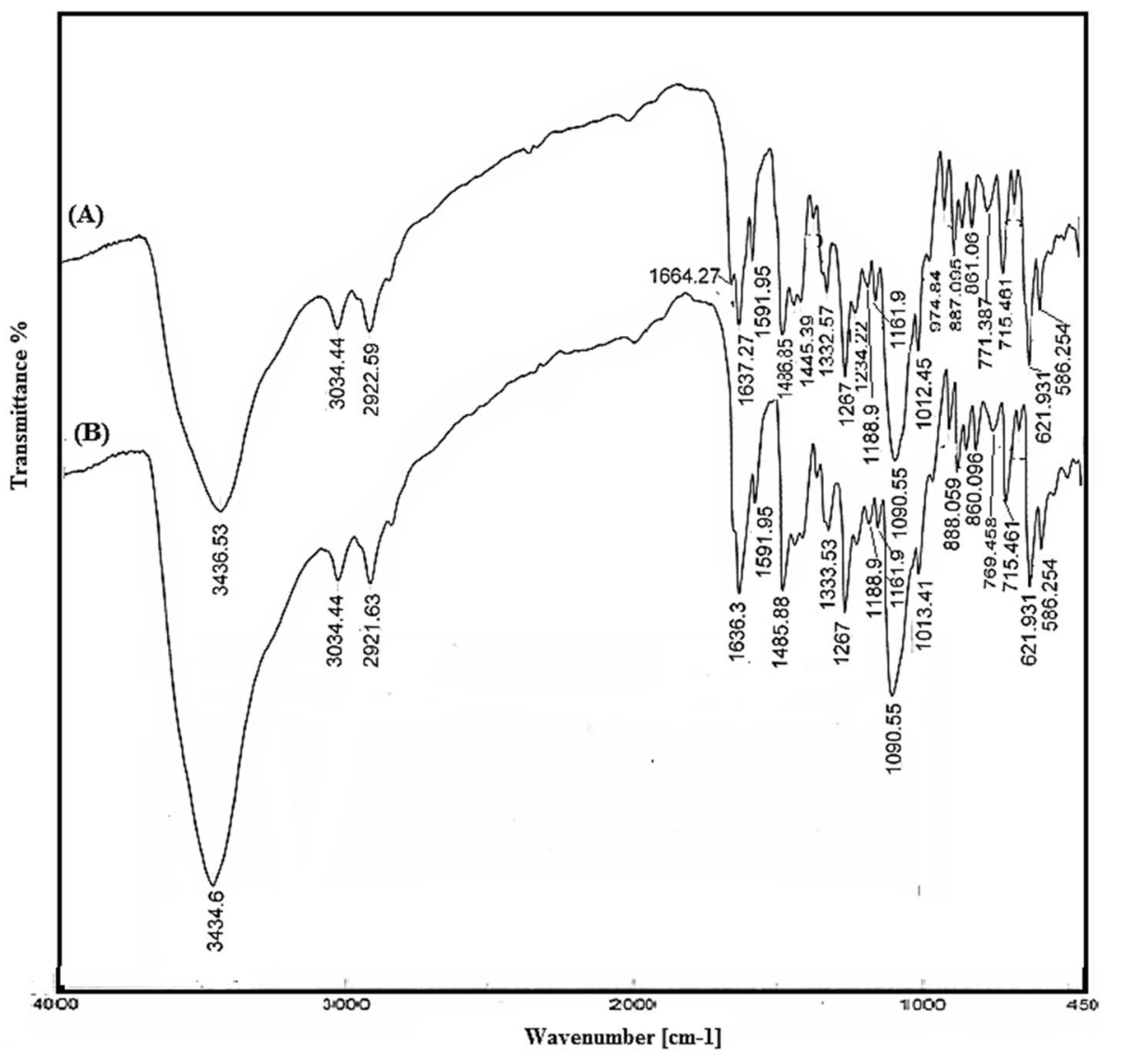


Fig. 9 SEM images of ARS/ XAD-2010 (a), U-loaded ARS/ XAD-2010 (b) and Th- loaded ARS/XAD-2010 (c)
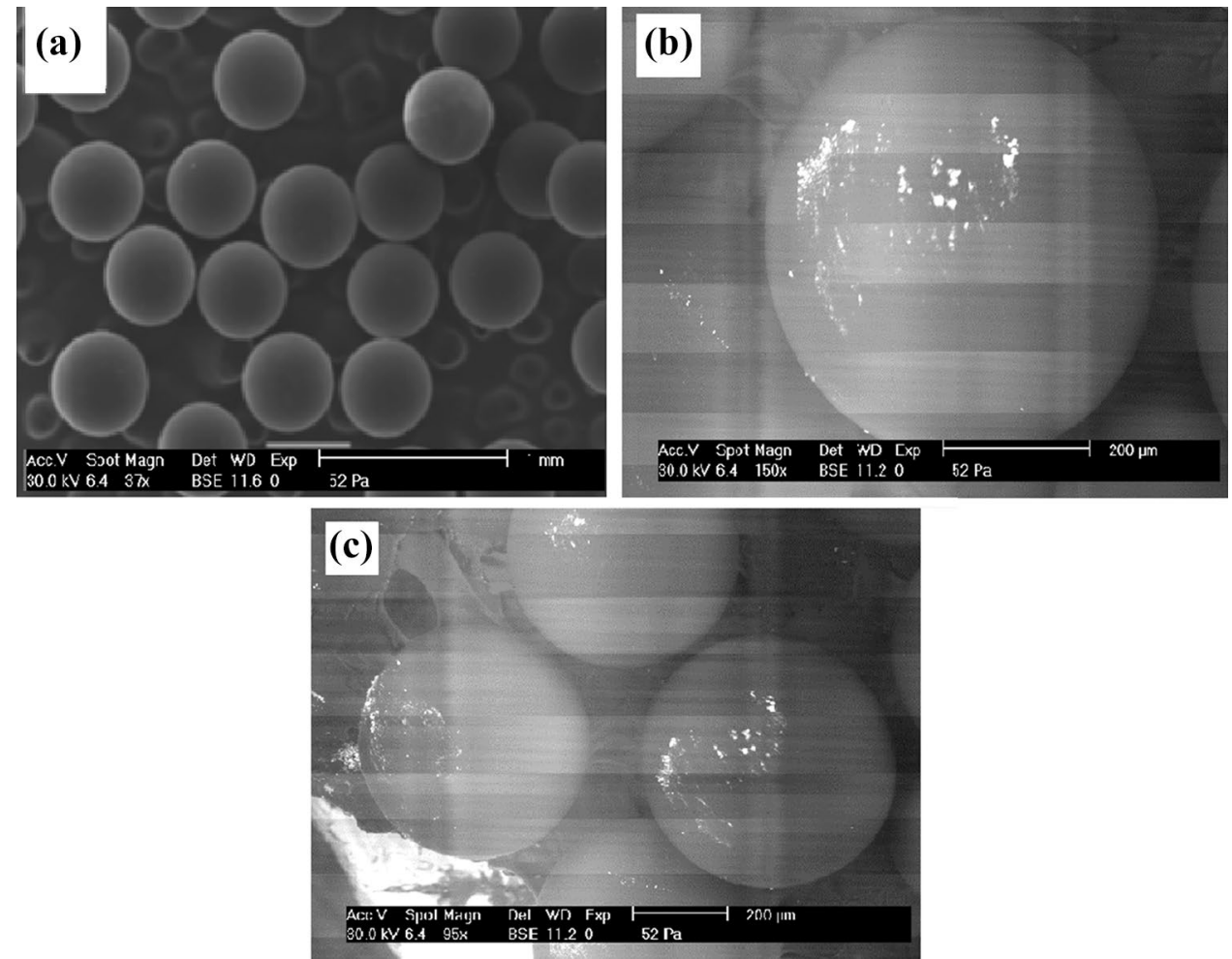

Here $\mathrm{Ce}\left(\mathrm{mg} \mathrm{L}^{-1}\right)$ is the equilibrium concentration of metal in the liquid phase, $q_{\max }\left(\mathrm{mg} \mathrm{g}^{-1}\right)$ is the monolayer capacity in model of langmuir, $K_{L}\left(\mathrm{~L} \mathrm{mg}^{-1}\right)$ is the Langmuir equilibrium constant, $k_{\mathrm{f}}$ and $n$ are characteristic Freundlich constants related to the relative sorption capacity of the sorbent and sorption intensity, respectively.

The linear plots of $\left(C_{e} / q_{e}\right)$ versus $C_{e}$ for Langmuir isotherm (Fig. 10a, b) or $\log q_{e}$ versus $\log C_{e}$ for Freundlich isotherm (Fig. 10c, d) give the constants of these models, from slope and intercept, which are given in Table 4 and represented adsorption properties of uranium and thorium from $0.01 \mathrm{M}$ perchloric acid towards synthesized EIR. Consequently, Langmuir isotherm model has better fitting experimental data performance in terms of higher correlation coefficient and conformity with equilibrium uranium and thorium adsorbed amount from perchlorate medium.

Dubinin-Radushkevich ( $D-R$ ) does not assume an energetically homogeneous surface and proposes a nonhomogenous distribution of adsorption sites. In particular, it assumes that the ionic species bind first with the most energetically favorable sites and that multilayer adsorption then occurs. The linear form of $D-R$ isotherm equation $[77,78]$ :

$\ln \mathrm{q}_{\mathrm{e}}=\ln \mathrm{q}_{\mathrm{m}}-\mathrm{k} \varepsilon^{2}$

where $q_{m}$ is the theoretical saturation capacity $\left(\mathrm{mg} \mathrm{g}^{-1}\right)$, $\mathrm{K}\left(\mathrm{mol}^{2} \mathrm{KJ}^{2}\right)$ is a constant related to the mean free energy of adsorption per mole of the adsorbate, $\varepsilon$ is the Polanyi potential $(\varepsilon=R T \ln (1+1 / C e))$, Ce is the equilibrium concentration of adsorbate in solution, $\mathrm{R}\left(8.314 \mathrm{~J} \mathrm{~mol}^{-1} \mathrm{~K}^{-1}\right)$ is the gas constant, and $\mathrm{T}$ is the absolute temperature. The $D-R$ constants $q_{m}$ and $K$ are calculated from the linear plots of $\ln \mathrm{q}_{\mathrm{e}}$ versus $\varepsilon^{2}$ from the intercept and slope (Fig. 11). The constant $\mathrm{K}$ gives an idea about the mean free energy $(\mathrm{E})$ of adsorption per molecule of the adsorbate when it is transferred to the surface of the solid from infinity in the solution and can be calculated from the relationship [77]:

$E=\frac{1}{\sqrt{2 K}}$

If the magnitude of $\mathrm{E}$ is between 8 and $16 \mathrm{~kJ} \mathrm{~mol}^{-1}$, the sorption process is supposed to proceed via chemisorption but if $\mathrm{E}$ is less than $8 \mathrm{~kJ} \mathrm{~mol}^{-1}$, the sorption process is of physical nature $[79,80]$.

$\mathrm{E}$ for uranyl and thorium ions is 0.173 and $0.2 \mathrm{~kJ} \mathrm{~mol}^{-1}$ respectively (less than 1 ) implying that $\mathrm{U}(\mathrm{VI})$ and $\mathrm{Th}(\mathrm{IV})$ adsorption process proceeds via physisorption and the values of correlation coefficient $\left(R^{2}\right)$ are 0.85 and 0.86 at 298 K, respectively. Therefore, the Dubinin-Radushkevich $(D-R)$ isotherm model does not fit the adsorption processes of the uranium and thorium ions on the synthesized EIR. Finally, it is clear from Table 4 and Figs. 10 and 11 that the parameters of Langmuir isotherm model are closer to the experimental values than those fitted by other models. 

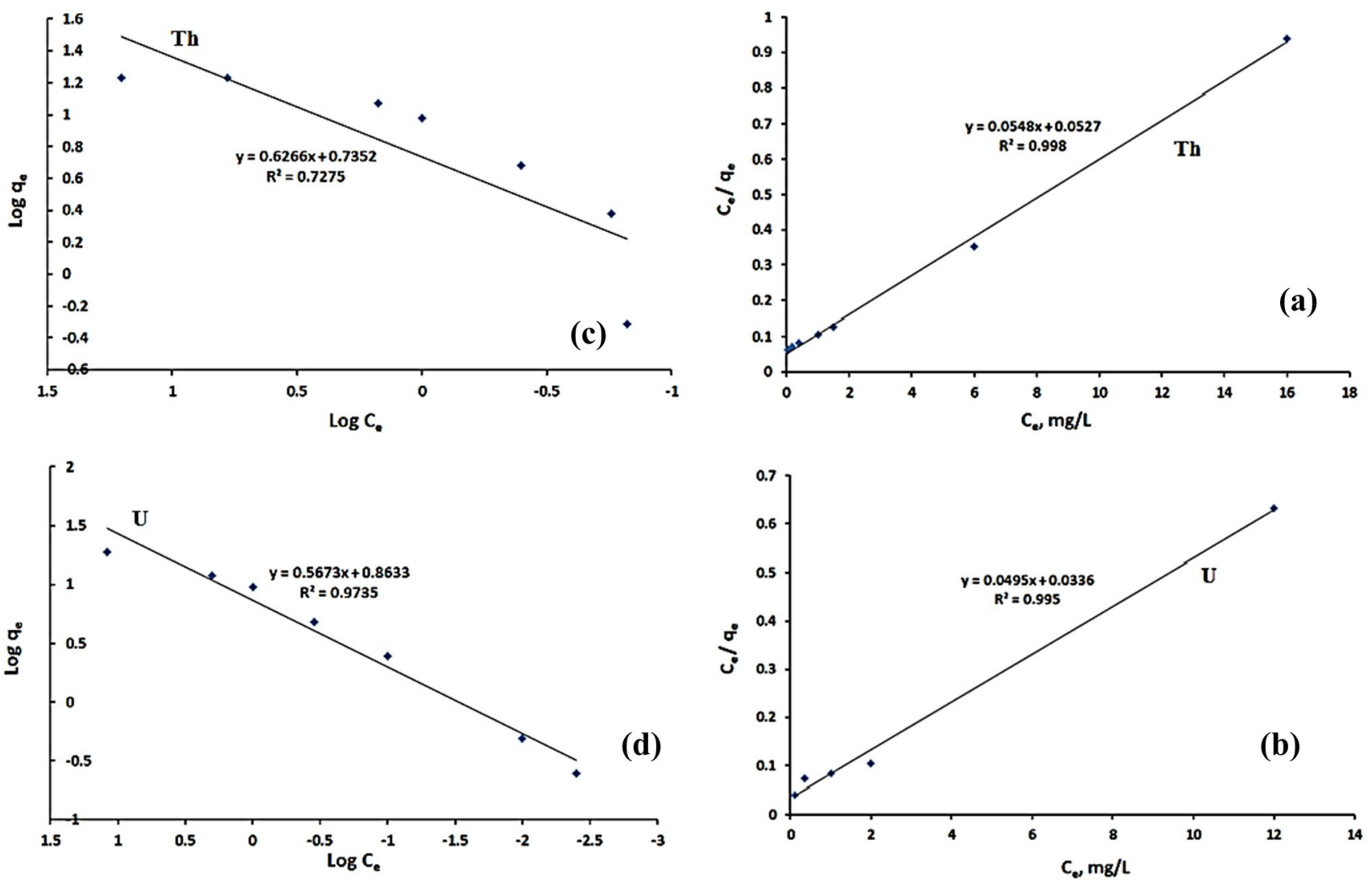

Fig. 10 Langmuir $(\mathbf{a}, \mathbf{b})$ and Freundlich (c, d) models of $\mathrm{U}$ and Th adsorption by synthesized EIR (Adsorption condition: $0.1 \mathrm{~g} \mathrm{EIR,} 50 \mathrm{~mL}$ of solution of $0.01 \mathrm{M}$ perchloric acid, $10 \mathrm{~min}$ contact time at $25^{\circ} \mathrm{C}$ )

Table 4 Isotherm parameters for the adsorption of $\mathrm{U}(\mathrm{VI})$ and Th(IV) ions onto synthesized EIR (ARS/XAD-2010)

\begin{tabular}{|c|c|c|c|c|c|c|c|}
\hline \multirow[t]{2}{*}{ Metal ions } & \multirow{2}{*}{$\begin{array}{l}\text { Exp. } q_{\max } \\
\left(\mathrm{mg} \mathrm{g}^{-1}\right)\end{array}$} & \multicolumn{3}{|c|}{ Langmuir parameters } & \multicolumn{3}{|c|}{ Freundlich parameters } \\
\hline & & $q_{\max }\left(\mathrm{mg} \mathrm{g}^{-1}\right)$ & $K_{\mathrm{L}}\left(\mathrm{L} \mathrm{mg}^{-1}\right)$ & $R^{2}$ & $n$ & $K_{\mathrm{f}}\left(\mathrm{mg} \mathrm{g}^{-1}\right)$ & $R^{2}$ \\
\hline $\mathrm{U}(\mathrm{VI})$ & 19 & 20.20 & 1.47 & 0.995 & 1.76 & 7.30 & 0.973 \\
\hline $\operatorname{Th}(\mathrm{IV})$ & 17 & 18.25 & 1.04 & 0.998 & 1.59 & 5.44 & 0.727 \\
\hline
\end{tabular}

These showed that Langmuir isotherm model could well describe the adsorption equilibrium of uranium and thorium ions on the resin.

\subsection{Effect of temperature (thermodynamics studies)}

For evaluation of the effect of temperature on adsorption of $\mathrm{U}(\mathrm{VI})$ and Th(IV) from perchloric acid (0.01 M) using synthesized EIR (ARS/XAD-2010), the adsorption process was conducted in a series of batch experiments under various temperatures ranging from 25 to $65^{\circ} \mathrm{C}$. The other parameters were as follows: concentration of each uranium and thorium $0.5 \mathrm{mg} \mathrm{L}^{-1}$, EIR amount $0.1 \mathrm{~g}$, solution volume $50 \mathrm{~mL}$. As seen from Fig. 12, heating in the examined range only slightly affects the adsorption. Therefore, $25^{\circ} \mathrm{C}$ can be considered as the optimum temperature for uranium adsorption experiments.

According to Lima et al. 2019 [81], the accurate estimation of thermodynamic parameters for adsorption system needs a correct equilibrium thermodynamic constant $\left(\mathrm{K}_{\mathrm{e}}^{0}\right)$ to be used in Van't Hoof equation. So, it is necessary to obtain the isotherms of adsorption at several temperatures and for the best isotherm model obtain the equilibrium constant $\left(\mathrm{K}_{\text {isotherm }}\right)$. Then, this $\mathrm{K}_{\text {isotherm }}$ should have their value converted from $\mathrm{L} \mathrm{mg}^{-1}$ into $\mathrm{L} \mathrm{mol}^{-1}$. In that situation, the best isotherm model that was adjusted to the equilibrium data was the Langmuir model. Therefore, the $\mathrm{k}_{\mathrm{L}}\left(\mathrm{L} \mathrm{mol}^{-1}\right)$ was used in the Van't Hoof equation, in order to estimate the thermodynamic parameters $(\Delta H, \Delta S$, and $\Delta \mathrm{G})[81]$ :

$\mathrm{K}_{\mathrm{e}}^{0}=\mathrm{K}_{\mathrm{L}} / \gamma$ 
Fig. 11 The Dubinin-Radushkevich (D-R) isotherm model of uranium (a) and thorium (b) adsorption on synthesized EIR (Adsorption condition: $0.1 \mathrm{~g}$ EIR, $50 \mathrm{~mL}$ of solution of $0.01 \mathrm{M}$ perchloric acid, 10 min contact time at $25^{\circ} \mathrm{C}$ )

Fig. 12 Effect of temperature on the adsorption efficiency of uranium and thorium using synthesized EIR (ARS/XAD2010) adsorbent (adsorption condition: $50 \mathrm{~mL} 0.5 \mathrm{mg} \mathrm{L}^{-1}$ of each uranium $(\mathrm{pH} 4)$ and thorium ( $\mathrm{pH} 2)$ ions solution, $0.01 \mathrm{M}$ perchloric acid, $0.1 \mathrm{~g}$ EIR, 10 min contact time)
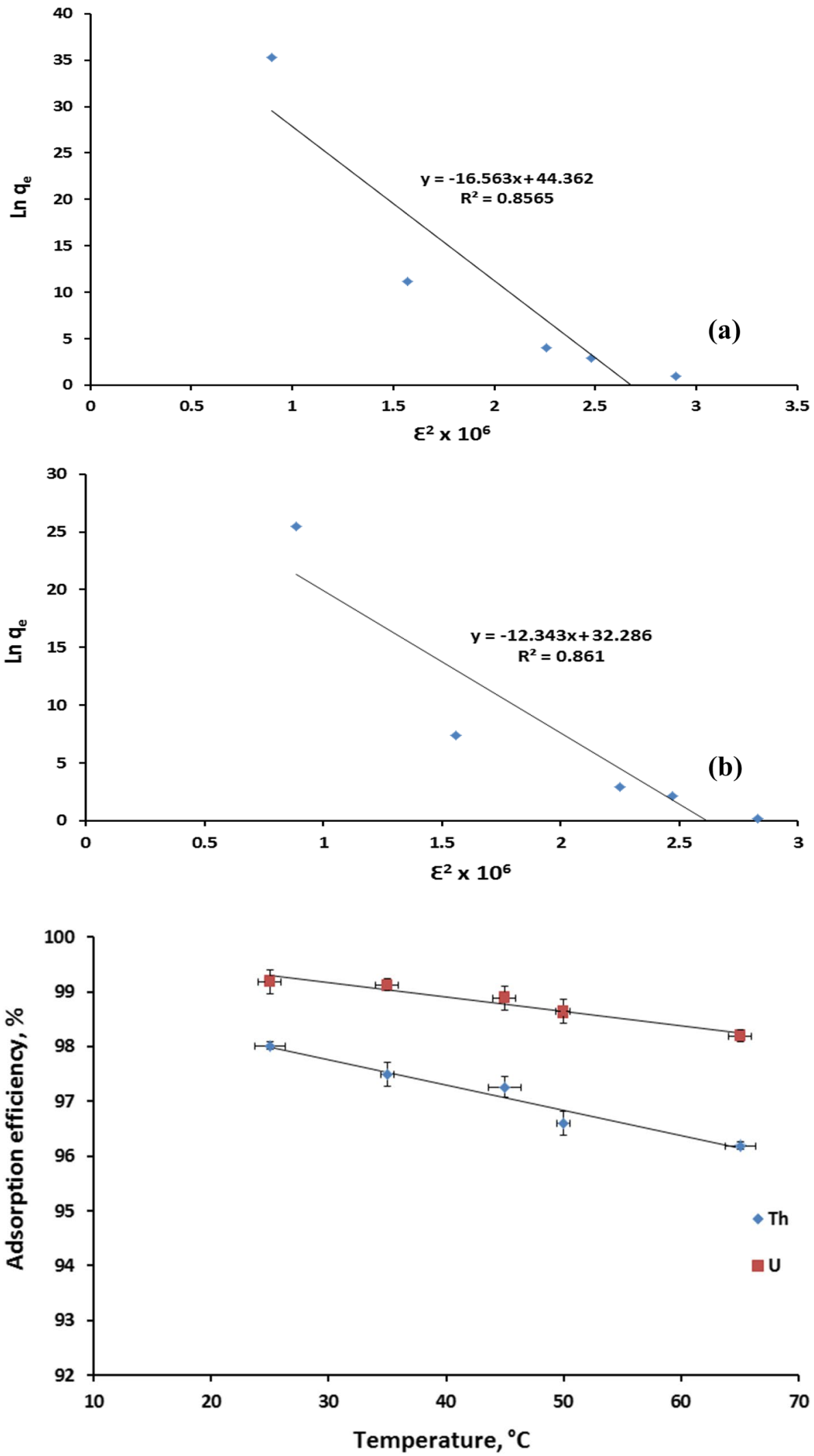

(17) $\Delta G=\Delta H-T \Delta S$ 
where $\mathrm{K}_{\mathrm{e}}^{0}\left(\mathrm{~L} \mathrm{~mol}^{-1}\right)$ is the thermodynamic equilibrium constant, $\gamma$ is the coefficient of activity, and the slope and intercept of the linear relation between $\ln \mathrm{K}_{\mathrm{e}}^{0}$ and $T^{-1}$ (Fig. 13) were used for calculation of enthalpy $\left(\Delta H, \mathrm{~kJ} \mathrm{~mol}^{-1}\right)$ and entropy $\left(\Delta S, \mathrm{~J} \mathrm{~mol}^{-1} \mathrm{~K}^{-1}\right)$ respectively. The negative value of $\Delta \mathrm{H}\left(-9.43 \mathrm{~kJ} \mathrm{~mol}^{-1}\right.$ for $\mathrm{U}$ and $-10.27 \mathrm{~kJ} \mathrm{~mol}^{-1}$ for Th) indicated that the adsorption process of $\mathrm{U}(\mathrm{VI})$ and $\mathrm{Th}(\mathrm{IV})$ by EIR was an exothermic reaction. The values of $\Delta S$ are $75.95 \mathrm{~J} \mathrm{~mol}^{-1} \mathrm{~K}^{-1}$ for $\mathrm{U}$ and $69.23 \mathrm{~J} \mathrm{~mol}^{-1} \mathrm{~K}^{-1}$ for Th. Negative Gibbs free energy $\Delta G$ value $\left(-32.06 \mathrm{~kJ} \mathrm{~mol}^{-1}\right.$ for $\mathrm{U}$ and $-30.9 \mathrm{~kJ} \mathrm{~mol}^{-1}$ for Th) demonstrated the spontaneous property of this adsorption [82-84].

\subsection{Interference effect}

Studying the interference effect was necessary for spectrophotometric determination of thorium and uranium in different geological rock samples. Some of the common cations which are associated with studied metals and may show sorption behavior on the ARS-modified resin interferes during their spectrophotometric determination namely, $\mathrm{Na}^{+}, \mathrm{K}^{+}, \mathrm{Ca}^{2+}, \mathrm{Mg}^{2+}, \mathrm{Al}^{3+}, \mathrm{Mn}^{2+}, \mathrm{Fe}^{3+}, \mathrm{Cr}^{6+}, \mathrm{VO}^{2+}$, $\mathrm{Cu}^{2+}, \mathrm{Co}^{3+}, \mathrm{Sr}^{2+}$, and $\mathrm{Ln}^{3+}$.

In the present experimental section, the effects of the above listed cations were studied by adding different volumes from their working solutions to a constant concentration of each uranium and thorium $\left(1 \mu \mathrm{g} \mathrm{mL}^{-1}\right)$. The absorbances of these mixtures were measured in aqueous solutions after contacting with ARS/XAD-2010 adsorbent at the optimized conditions. From the obtained results (Table 5), it was found that;
Table 5 Effect of foreign ions on the adsorption of uranium and thorium from perchlorate solution with equal concentration of $1 \mu \mathrm{g} \mathrm{mL}^{-1}$ for both analytes

\begin{tabular}{lrr}
\hline Interfering ion & \multicolumn{2}{l}{ Tolerance } \\
& ratio \\
\cline { 2 - 3 } & $\mathrm{Th}(\mathrm{IV})$ & $\mathrm{U}(\mathrm{VI})$ \\
\hline $\mathrm{Ca}^{2+}$ & 5000 & 1000 \\
$\mathrm{Mg}^{2+}$ & 5000 & 1000 \\
$\mathrm{Na}^{+}$ & 5000 & 1000 \\
$\mathrm{~K}^{+}$ & 5000 & 1000 \\
$\mathrm{Sr}^{2+}$ & 5000 & 1000 \\
$\mathrm{Al}^{3+}$ & 5000 & 1000 \\
$\mathrm{Mn}^{2+}$ & 5000 & 1000 \\
$\mathrm{Fe}^{3+}$ & 500 & 1000 \\
$\mathrm{Co}^{2+}$ & 500 & 200 \\
$\mathrm{Cu}^{2+}$ & 500 & 200 \\
$\mathrm{Zn}^{2+}$ & 500 & 200 \\
$\mathrm{Cd}^{2+}$ & 500 & 200 \\
$\mathrm{VO}^{2+}$ & 300 & 100 \\
$\mathrm{Ni}^{2+}$ & 250 & 100 \\
$\mathrm{~Pb}^{2+}$ & 500 & 200 \\
$\mathrm{Ln}^{3+}$ & 500 & 100 \\
\hline & &
\end{tabular}

1. The alkaline earth metals did not interfere on the preconcentration process.

2. The cations such as $\mathrm{Cu}^{2+}, \mathrm{Zn}^{2+}, \mathrm{Fe}^{3+}, \mathrm{Co}^{3+}, \mathrm{Pb}^{2+}$ and $\mathrm{Cd}^{2+}$, start to show their significant interference at concentration limits above 500 and 200 times greater than this of $T h$ and $U$ respectively.

3. The cations such as $\mathrm{VO}^{2+}, \mathrm{Ni}^{2+}$ and $\mathrm{Ln}^{3+}$ start to show their significant interference at concentrations 100 times greater than this of $U$ and 300,250, 500 respectively times greater than this of Th.
Fig. 13 The plot of $L n K_{d}$ versus $1 / T$ of the uranium and thorium adsorption upon synthesized EIR (Adsorption condition: $0.1 \mathrm{~g}$ EIR, $50 \mathrm{~mL}$ $0.5 \mathrm{mg} \mathrm{L}^{-1}$ of each uranium $(\mathrm{pH} 4)$ and thorium $(\mathrm{pH} 2)$ ions solution, $0.01 \mathrm{M}$ perchloric acid, $0.1 \mathrm{~g}$ EIR, 10 min contact time, at $25^{\circ} \mathrm{C}$ )

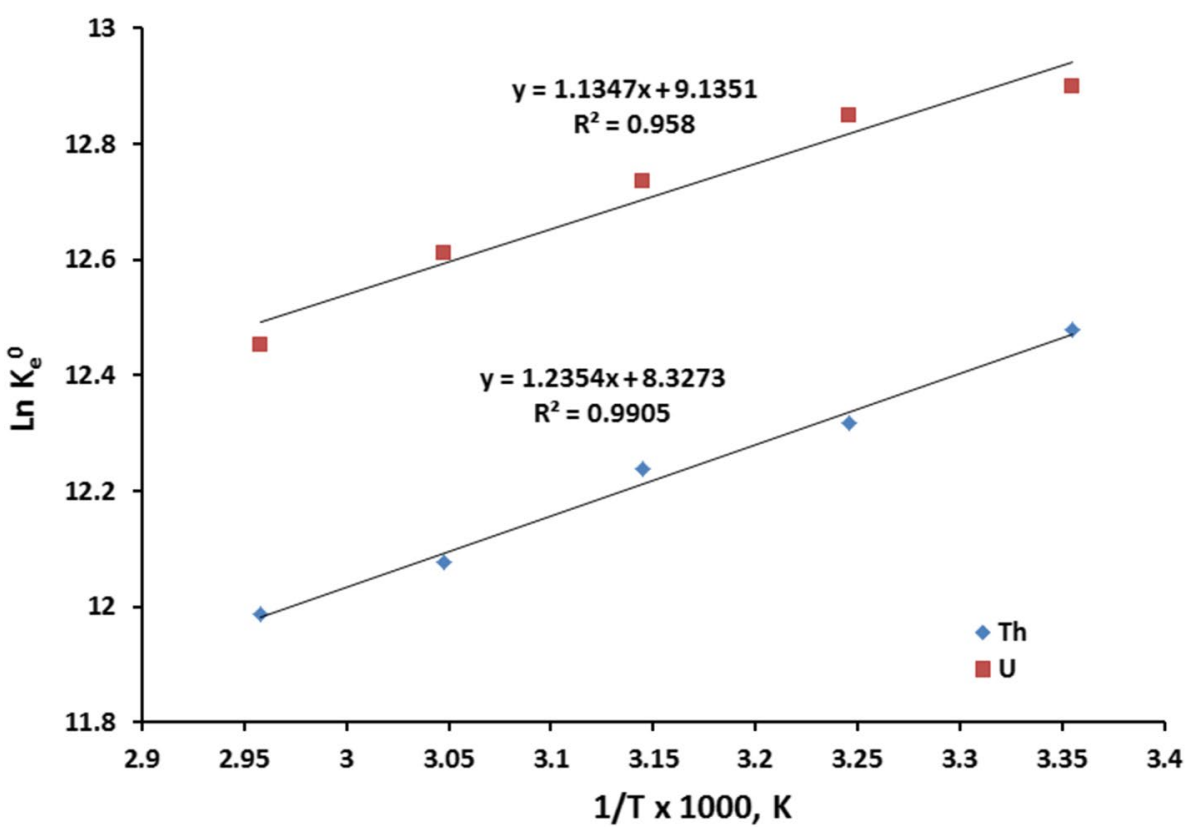

SN Applied Sciences 


\subsection{Elution studies}

Quantitative desorption of U(VI) and Th(IV) was performed with various eluting agents such as hydrochloric acid, ammonium oxalate, ammonium carbonate, and nitric acid which form stable complexes with uranium and thorium $[22,55,57,84,85]$. For this purpose, $10 \mathrm{~mL}$ aliquots of each eluting agent $(1 \mathrm{M})$ were treated with $0.1 \mathrm{~g}$ portions of loaded EIR at $298 \pm 1 \mathrm{~K}$ for $10 \mathrm{~min}$. The elution of metal ions with ammonium oxalate was $56 \%$ for Th and $30 \%$ for $U$. The elution with ammonium carbonate was $6 \%$ for Th and $68 \%$ for U. while with hydrochloric and nitric acid, it was $99.4-32.5 \%$ for Th and 99.6-43.4\% for U respectively. Hydrochloric acid was selected for optimum elution experiments.

\subsection{EIR reusability}

The EIR reusability was checked by subjecting the synthesized EIR (ARS/XAD-2010) to several loading and elution experiments. The capacity of the synthesized EIR (ARS/XAD-2010) was found to be practically constant (variation $<1 \%$ ) after its repeated use for more than 40 runs, thus indicating the multiple use of EIR is feasible.

\subsection{Application of proposed method for standard geological and granitic samples}

The proposed method was applied for preconcentration and determination of $\mathrm{U}(\mathrm{VI})$ and $\mathrm{Th}(\mathrm{IV})$ in different samples including reference and geological materials to verify applications and validations of it. The samples were firstly decomposed by Afifi et al. and Fouad et al. $[86,87]$ to overcome the high concentration of major oxides. The serious interference from above studied cations was avoided by masking with potassium cyanide $\left(1 \times 10^{-3} \mathrm{M}\right)$ [88], Then, uranium and thorium was separated from acidic solution using synthesized EIR (ARS/XAD-2010) adsorbent at optimum conditions and analyzed in the eluted solutions spectrophotometrically with good accuracy (Tables 6, 7). Thus, these results indicated that the proposed method is accurate, simple and cost-effective for analyzing ore samples containing uranium and thorium.

\section{Summary and conclusions}

A combination between spectrophotometric procedure and separation of $\mathrm{U}(\mathrm{VI})$ and $\mathrm{Th}(\mathrm{IV})$ ions by a high stable EIR is described. The new EIR was prepared by impregnating alizarin red S onto Amberlite XAD-2010 beads. The maximum sorption capacity respect to interested
Table 6 Comparison of uranium and thorium concentrations in standard reference rock samples and found using present method

\begin{tabular}{|c|c|c|c|c|c|c|}
\hline Standard sample & $\begin{array}{l}\text { Certified } \\
\text { value (ppm) }\end{array}$ & $\begin{array}{l}\text { Concentration of } \mathrm{U} \text {, Th found } \\
\text { using present method (ppm) }\end{array}$ & SD & SE & Error \% & Accuracy \\
\hline \multirow[t]{6}{*}{ DL-1 $a^{a}$} & $76 \mathrm{Th}$ & 75.3 & 0.57 & 0.33 & 0.44 & \pm 0.64 \\
\hline & & 75.5 & & & & \\
\hline & & 76.6 & & & & \\
\hline & $116 \mathrm{U}$ & 115.2 & 0.89 & 0.51 & 0.44 & \pm 0.88 \\
\hline & & 115.6 & & & & \\
\hline & & 116.9 & & & & \\
\hline \multirow[t]{6}{*}{$\mathrm{DH}-1 \mathrm{a}^{\mathrm{a}}$} & 91Th & 90.3 & 0.62 & 0.36 & 0.39 & \pm 0.62 \\
\hline & & 90.6 & & & & \\
\hline & & 91.5 & & & & \\
\hline & $2629 U$ & 2627.5 & 1.05 & 0.61 & 0.023 & \pm 0.95 \\
\hline & & 2625.6 & & & & \\
\hline & & 2626.7 & & & & \\
\hline \multirow[t]{6}{*}{$\mathrm{Nim} . \mathrm{G}^{\mathrm{b}}$} & $51 \mathrm{Th}$ & 50.6 & 0.73 & 0.42 & 0.83 & \pm 0.62 \\
\hline & & 51.5 & & & & \\
\hline & & 50.3 & & & & \\
\hline & $15 U$ & 15.5 & 0.36 & 0.21 & 1.33 & \pm 0.36 \\
\hline & & 15.3 & & & & \\
\hline & & 16.0 & & & & \\
\hline
\end{tabular}

${ }^{a}$ Certified values reported by Canadian Central for Mineral and Energy Technology standards (CANMET), certifying agency. $S D$ standard deviation, $S E$ standard error

${ }^{b}$ Certified values reported by SA Bureau of standards P/Bag X191, Pretoria 0001 (SARM1) 
Table 7 Comparison between uranium and thorium concentrations in the granitic rock samples using the present method

\begin{tabular}{|c|c|c|c|c|c|c|}
\hline $\begin{array}{l}\text { Granitic } \\
\text { sample ID }\end{array}$ & $\begin{array}{l}\text { Expected U, Th con- } \\
\text { centration (ppm) }\end{array}$ & $\begin{array}{l}\text { Concentration of } U \text {, Th found } \\
\text { using present method (ppm) }\end{array}$ & SD & SE & Error \% & Accuracy \\
\hline \multirow[t]{6}{*}{ M40 } & $412 \mathrm{Th}$ & 413.0 & 0.60 & 0.35 & 0.08 & \pm 0.40 \\
\hline & & 411.2 & & & & \\
\hline & & 412.5 & & & & \\
\hline & $40 \mathrm{U}$ & 40.6 & 0.57 & 0.33 & 0.81 & \pm 0.15 \\
\hline & & 41.4 & & & & \\
\hline & & 40.3 & & & & \\
\hline \multirow[t]{6}{*}{ M50 } & 160.2 Th & 161.0 & 0.70 & 0.40 & 0.25 & \pm 0.15 \\
\hline & & 159.7 & & & & \\
\hline & & 159.9 & & & & \\
\hline & $50 \mathrm{U}$ & 51.5 & 0.73 & 0.42 & 0.83 & \pm 0.624 \\
\hline & & 50.6 & & & & \\
\hline & & 50.3 & & & & \\
\hline \multirow[t]{6}{*}{ M53 } & $290.5 \mathrm{Th}$ & 289.2 & 0.35 & 0.20 & 0.07 & \pm 0.35 \\
\hline & & 288.9 & & & & \\
\hline & & 288.5 & & & & \\
\hline & $20 \mathrm{U}$ & 20.8 & 0.31 & 0.17 & 0.85 & \pm 0.24 \\
\hline & & 20.6 & & & & \\
\hline & & 21.2 & & & & \\
\hline \multirow[t]{6}{*}{ T77 } & $113 \mathrm{Th}$ & 113.8 & 0.87 & 0.50 & 0.45 & \pm 0.87 \\
\hline & & 112.4 & & & & \\
\hline & & 112.2 & & & & \\
\hline & $30 \mathrm{U}$ & 30.7 & 0.36 & 0.21 & 0.67 & \pm 0.36 \\
\hline & & 30.9 & & & & \\
\hline & & 31.4 & & & & \\
\hline \multirow[t]{6}{*}{ T78 } & 79 Th & 78.5 & 0.70 & 0.40 & 0.51 & \pm 0.70 \\
\hline & & 79.6 & & & & \\
\hline & & 78.3 & & & & \\
\hline & $60 \mathrm{U}$ & 60.5 & 0.74 & 0.43 & 0.70 & \pm 0.74 \\
\hline & & 61.6 & & & & \\
\hline & & 60.2 & & & & \\
\hline
\end{tabular}

metal ions was acquired by conducting a fixed EIR (ARS/ XAD-2010) weight $(0.1 \mathrm{~g})$ with $50 \mathrm{~mL}$ of each uranium $(\mathrm{pH} 4)$ and thorium $(\mathrm{pH} 2)$ ions solution in perchloric acid $(0.01 \mathrm{M})$ for $10 \mathrm{~min}$ contact time at room temperature. Langmuir isotherm model has better fitting experimental data with a maximum adsorption capacity of $20.2 \mathrm{mg} \mathrm{g}^{-1}$ for $\mathrm{U}(\mathrm{VI})$ and $18.25 \mathrm{mg} \mathrm{g}^{-1}$ for Th(IV). The adsorption process of each metal ion by synthesized Alizarin Red S -impregnated XAD-2010 showed an exothermic pseudo-second-order adsorption process. The loaded metal ions were afterward completely eluted using one mole of $10 \mathrm{~mL} \mathrm{HCl}$ solution using 10 min contact time. The tolerance limits for several metal ions on Alizarin Red S -impregnated XAD-2010 were calculated, giving high tolerance limit. The optimized method was applied to reference and different rock types bearing thorium and uranium with good accurate results.

\section{Compliance with ethical standards}

Conflict of interest The authors declare that they have no conflict of interest.

\section{References}

1. Agency for Toxic Substances and Disease Registry, U.S. Public Health Service, New York (2008) Health consultation. Depleted uranium at Hawaiian military sites; Schofield Barracks Impact Area; Makua Military Reservation, Pohakuloa Training Area on Islands of Oahu and Hawaii

2. Jain V, Pandya R, Pillai S et al (2006) Solid phase extraction, preconcentration and sequential separation of $\mathrm{U}(\mathrm{VI}), \mathrm{Th}(\mathrm{IV})$, $\mathrm{La}$ (III) and Ce(III) by Octa-O-methoxy resorcin[4]arene based Amberlite XAD-4 chelating resin. Talanta 70:257-266. https:// doi.org/10.1016/j.talanta.2006.02.032

3. Welz B, Sperling M (1999) Atomic absorption spectrometry. Wiley-VCH, New York 
4. Tamborini G (2004) SIMS analysis of uranium and actinides in microparticles of different origin. Microchim Acta 145:237-242. https://doi.org/10.1007/s00604-003-0160-8

5. Dean J (1997) Atomic absorption and plasma spectroscopy. Wiley, London

6. Marczenko Z, Balcerzak M (2000) Separation, preconcentration and spectrophotometry in inorganic analysis, vol 10. Elsevier, Amsterdam

7. Perkampus H (1992) UV-Vis spectroscopy and its applications, vol 33. Springer, Berlin

8. Sengupta A, Ippili T, Jayabun $S$ et al (2016) ICP-AES determination of trace metallic constituents in thorium matrix after preferential extraction of thorium using TBP, TOPO and DHOA: a comparative study. J Radioanal Nucl Chem 310(1):59-67. https ://doi.org/10.1007/s10967-016-4790-9

9. Kato K, Ito M, Watanabe K (2000) Determination of thorium and uranium in activated concrete by inductively coupled plasma mass spectrometry after anion-exchange separation. Fresen J Anal Chem 366:54. https://doi.org/10.1007/s002160050011

10. Torgov V, Demidova M, Saprykin A et al (2002) Extraction preconcentration of uranium and thorium traces in the analysis of bottom sediments by inductively coupled plasma mass spectrometry. Anal Chem 57:303. https://doi.org/10.1023/A:10149 42112864

11. Tolmachyov S, Kuwabara J, Noguchi H (2004) Flow injection extraction chromatography with ICP-MS for thorium and uranium determination in human body fluids. J Radioanal Nucl Chem 261:125. https://doi.org/10.1023/B:JRNC.0000030945 $.53499 .1 \mathrm{C}$

12. Ghaedi M, Asadpour E, Vafaie A (2006) Simultaneous preconcentration and determination of copper, nickel, cobalt, lead and iron content using a surfactant coated alumina. Bull Chem Soc Jpn 79:432-436. https://doi.org/10.1246/bcsj.79.432

13. Lemos V, David G, Santos L (2006) Synthesis and application of XAD-2/Me-BTAP resin for on-line solid phase extraction and determination of trace metals in biological samples by FAAS. J Braz Chem Soc 17:697-704. https://doi.org/10.1590/S0103 $-50532006000400010$

14. Gupta N, Sengupta A, Gupta A et al (2018) Biosorption-an alternative method for nuclear waste management: a critical review. J Environ Chem Eng 6(2):2159-2175. https://doi.org/10.1016/j. jece.2018.03.021

15. Sengupta A, Gupta N (2017) MWCNTs based sorbents for nuclear waste management: a review. J Environ Chem Eng 5(5):50995114. https://doi.org/10.1016/j.jece.2017.09.054

16. Dubey R, Bhalotra A, Gupta M et al (1998) Differential-pulse polarographic-determination of uranium $(\mathrm{VI})$ in standard and synthetic samples after adsorption of its quinolin-8-olate on microcrystalline naphthalene. Anal Chim 88:719-729

17. Seki T, Oguma K (2004) Determination of uranium in natural waters and high-purity aluminum by flow-injection on-line preconcentration and ICP-MS detection. Bunseki Kagaku 53:353357. https://doi.org/10.2116/bunsekikagaku.53.353

18. Rao T, Metilda P, Mary Gladis J (2006) Preconcentration techniques for uranium(VI) and thorium(IV) prior to analytical determination: an overview. Talanta 68:1047-1064. https://doi. org/10.1016/j.talanta.2005.07.021

19. Ghaedi M, Niknam K, Zamani S et al (2013) Silica chemically bonded N-propyl kriptofix 21 and 22 with immobilized palladium nanoparticles for solid phase extraction and preconcentration of some metal ions. Mater Sci Eng C 33:3180-3189. https ://doi.org/10.1016/j.msec.2013.03.045

20. Gladis J, Rao T (2002) Solid phase extractive preconcentration of uranium on to 5,7-dichloroquinoline-8-ol modified naphthalene. Anal Lett 35:501-515. https://doi.org/10.1081/AL-12000 2683
21. Hosseini M, Hosseini-Bandegharaei A (2011) Comparison of sorption behavior of Th(IV) and U(VI) on modified impregnated resin containing quinizarin with that conventional prepared impregnated resin. J Hazard Mater 190:755-765. https://doi. org/10.1016/j.jhazmat.2011.03.111

22. Hosseini-Bandegharaei A, Hosseini M, Jalalabadi $Y$ et al (2011) A novel extractant- impregnated resin containing carminic acid for selective separation and pre-concentration of uranium(VI) and thorium(IV). Int J Environ Anal Chem 93:108-124. https:// doi.org/10.1080/03067319.2011.620706

23. Korn M, Santos A, Jaegera H et al (2004) Copper, zinc and manganese determination in saline samples employing FAAS after separation and preconcentration on Amberlite XAD-7 and Dowex 1 X-8 loaded with alizarin red SJ. Braz Chem Soc 15(2):212-218

24. Hosseini M, Bazrafshan A, Hosseini-Bandegharaei A (2016) A novel solvent-impregnated resin containing 3-hydroxy-2-naphthoic acid for stepwise extraction of Th(IV) and U(VI) over other coexistence ions. Sep Sci Technol 51(8):1328-1335. https://doi. org/10.1080/01496395.2016.1147465

25. Soylak M, Elci L, Dogan M (2001) Solid phase extraction of trace metal ions with Amberlite XAD resins prior to atomic absorption spectrometric analysis. J Trace Microprobe Technol 19:329-344. https://doi.org/10.1081/TMA-100105049

26. Lemos V, Nunes L, Baliza P et al (2004) On-line solid phase extraction system for cadmium preconcentration and determination by flame atomic absorption spectroscopy. Can J Anal Sci Spectrosc 49:24-30

27. Qadeer R, Hanif J, Khan M et al (1995) Uptake of uranium ions by molecular sieve. Radiochim Acta 68:197-201

28. Landgraf W, Li N, Benson J (2003) Polymer microcarrier exhibiting zero-order release. Drug Deliv Technol 3:1-12

29. Sigma-Aldrich (2006) Amberlite XAD polimeric resins. http:// www.sigmaaldrich.com/sigma/product\%20information $\% 20$ sheet/xad7pis.pdf. Accessed 10 Aug 2006

30. Bulut V, Duran C, Tufekci M et al (2007) Speciation of $\mathrm{Cr}$ (III) and $\mathrm{Cr}(\mathrm{VI})$ after column solid phase extraction on Amberlite XAD2010. J Hazard Mater 143:112-117. https://doi.org/10.1016/j. jhazmat.2006.08.074

31. Duran C, Gundogdu A, Bulut V et al (2007) Separation and enrichment of gold(III) from environmental samples prior to its flame atomic absorption spectrometric determination. J Hazard Mater 149:317-323. https://doi.org/10.1016/j.jhazm at.2007.03.083

32. Duran C, Senturk H, Gundogdu A et al (2007) Determination of some trace metals in environmental samples by flame AAS following solid phase extraction with Amberlite XAD-2000 resin after complexing with 8-hydroxyquinoline. Chin J Chem 25:196-202. https://doi.org/10.1002/cjoc.200790040

33. Hosseini M, Hosseini-Bandegharaei A (2010) Selective extraction of Th(IV) over $\mathrm{U}(\mathrm{VI})$ and other co-existing ions using eosin B impregnated Amberlite IRA-410 resin beads. J Radioanal Nucl Chem 283:23-30. https://doi.org/10.1007/s10967-009-0037-3

34. Hosseini M, Hosseini-Bandegharaei A, Raissi H et al (2009) Sorption of $\mathrm{Cr}(\mathrm{VI})$ by Amberlite XAD-7 resin impregnated with brilliant green and its determination by quercetin as a selective spectrophotometric reagent. J Hazard Mater 169:52-57. https ://doi.org/10.1016/j.jhazmat.2009.03.058

35. Hosseini M, Hosseini-Bandegharaei A, Hosseini M (2009) Column-mode separation and pre-concentration of some heavy metal ions by solvent-impregnated resins containing quinizarin before the determination by flame atomic absorption spectrometry. Int J Environ Anal Chem 89:35-48. https://doi. org/10.1080/03067310802464948

36. Hosseini-Bandegharaei A, Hosseini M, Jalalabadi Y (2011) Removal of $\mathrm{Hg}$ (II) from aqueous solutions using a novel 
impregnated resin containing 1-(2-thiazolylazo)-2-naphthol (TAN). Chem Eng J 168:1163-1173. https://doi.org/10.1016/j. cej.2011.02.004

37. Hosseini-Bandegharaei A, Hosseini M, Sarw-Ghadi M et al (2010) Kinetics, equilibrium and thermodynamic study of $\mathrm{Cr}(\mathrm{VI})$ sorption into toluidine blue o-impregnated XAD-7 resin beads and its application for the treatment of wastewaters containing $\mathrm{Cr}(\mathrm{VI})$. Chem Eng J 160:190-198. https://doi. org/10.1016/j.cej.2010.03.040

38. Marczenko Z (1986) Separation and spectrophotometric determination of elements, vol 60. Wiley, New York

39. Leenheer A, Ruyter M, Steyaert H (1976) A method for the statistical evaluation of results in external quality control surveys. Clin Chim Acta 71:229-238. https://doi.org/10.1016/00098981(76)90535-0

40. Davis J (1986) In: Handbook of statistics and analysis in geology, 2nd edn. Wiley, New York, p 646

41. Christian G (1994) In: Handbook of analytical chemistry, 5th edn, chapter 2. Wiley, New York, pp 22-26

42. Muraviev D (1998) Surface impregnated sulfonate ion exchangers: preparation, properties and application. Solvent Extr Ion Exch 16:381-457. https://doi.org/10.1080/07366 299808934533

43. Muraviev D, Ghantous L, Valiente M (1998) Stabilization of solvent-impregnated resin capacities by different techniques. React Funct Polym 38:259-268. https://doi.org/10.1016/S1381 $-5148(98) 00075-3$

44. Hosseini-Bandegharaei A, Sarwghadi M, Heydarbeigi A et al (2013) Solid-phase extraction of trace amounts of uranium(VI) in environmental water samples using an extractant-impregnated resin followed by detection with UV-Vis spectrophotometry. J Chem 2013:1-10. https://doi.org/10.1155/2013/671564

45. Maihub A, El-ajaily M, Aboukrish M et al (2003) Synthesis and characterization of some homodinuclear mixed ligand complexes of Co(II) and Cu(II) part II. Jerash Res Stud 7(2):41-47

46. Khalifa M (1998) Selective separation of uranium using Alizarin Red S (ARS)-modified anion-exchange resin or by flotation of U-ARS chelate. Sep Sci Technol 33:2123-2141. https://doi. org/10.1080/01496399808545719

47. Wang G, Liu J, Wang X et al (2009) (Adsorption of uranium(VI) from aqueous solution onto cross-linked chitosan. J Hazard Mater 168:1053-1058

48. Anirudhan T, Rijith S (2012) Synthesis and characterization of carboxyl terminated poly (methacrylic acid) grafted chitosan/ bentonite composite and its application for the recovery of uranium(VI) from aqueous media. J Environ Radioact 106:819. https://doi.org/10.1016/j.jenvrad.2011.10.013

49. Atrees E, Metwally B, Demerdash M et al (2016) Sorption behavior of Pr and Nd upon chitosan benzoyl thiourea derivatives. J Radiat Res Appl Sci 9:207-216

50. Kalal H, Panahi H, Hoveidi $H$ et al (2012) Synthesis and application of Amberlite XAD-4 functionalized with alizarin red-s for preconcentration and adsorption of rhodium(III). Iran J Environ Health Sci Eng 9:1-9

51. Cheira $M$, Atia B, Kouraim M (2017) Uranium(VI) recovery from acidic leach liquor by Ambersep $920 \mathrm{U} \mathrm{SO}_{4}$ resin: kinetic, equilibrium and thermodynamic studies. J Radiat Res Appl Sci 10:307-319

52. Pakade V, Cukrowska E, Darkwa J et al (2012) Simple and efficient ion imprinted polymer for recovery of uranium from environmental samples. Water Sci Technol 65:728-736

53. Zhang $H$, Liang $H, C$ hen $Q$ et al (2013) Synthesis of a new ionic imprinted polymer for the extraction of uranium from seawater. J Radioanal Nucl Chem 298:1705-1712. https://doi. org/10.1007/s10967-013-2612-x
54. Li F, Li D, Li X et al (2016) Microorganism derived carbon microspheres for uranium removal from aqueous solution. Chem Eng J 284:630-639

55. Hosseini S, Rahmani-Sani A, Jalalabadi Y et al (2015) Preconcentration and determination of ultra-trace amounts of $\mathrm{U}(\mathrm{VI})$ and Th(IV) using titan yellow impregnated Amberlite XAD-7 resin. Int J Environ Anal Chem 95:277-290. https://doi.org/10.1080/03067 319.2015.1016009

56. Baes J, Mesmer R (1976) Hydrolysis of cations. Wiley, New York

57. Elsalamouny A, Desouky O, Mohamed S et al (2016) Evaluation of adsorption behavior for $\mathrm{U}(\mathrm{VI})$ and Th(IV) ions onto solidified mannich type material. J Dispers Sci Technol 38:860-865. https ://doi.org/10.1080/01932691.2016.1207546

58. Atia A (2005) Studies on the interaction of mercury(II) and uranyl(II) with modified chitosan resins. Hydrometallurgy 80:1322. https://doi.org/10.1016/j.hydromet.2005.03.009

59. Li W, Tao Z (2002) Biosorption of americium-241 by Saccharomyces cerevisiae. J Radioanal Nucl Chem 254:187-191. https:// doi.org/10.1023/A:1015276813386

60. Mishra S, Achary G, Das M (2012) Adsorption of Cu(II) by used aqua guard carbon(UAC). J Chem Pharm Res 4(2):1207-1216

61. Sharma I, Goyal D (2009) Kinetic modeling: chromium(III) removal from aqueous solution bymicrobial waste biomass. J Sci Ind Res 68:640-646

62. Ho Y, McKay G (1999) Pseudo-second order model for sorption processes. Process Biochem 34:451-465. https://doi. org/10.1016/S0032-9592(98)00112-5

63. Lagergren $S$ (1898) About the theory of so-called adsorption of soluble substance. Kungliga Svenska Vetenskapsakademiens Handlingar 24:1-39

64. Donia A, Atia A, Daher A et al (2011) Selective separation of U(VI) from its solutions using amine modified silica gel produced from leached zircon. Int J Miner Process 101:81-88

65. Weber W, Morris J (1963) Kinetics of adsorption on carbon from solution. J Sanit Eng Div Proc 89:31-59

66. Preetha C, Rao T (2006) Preconcentration of uranium(VI) by solid phase extraction onto dicyclohexano-18-crown-6 embedded benzophenone. J Radioanal Nucl Chem 267:265-270. https:// doi.org/10.1007/s10967-006-0042-8

67. Preetha C, Gladis J, Rao T (2002) Solid phase extractive preconcentration of thorium onto 5,7-dichloroquinoline-8-ol modified benzophenone. Talanta 58:701-709. https://doi.org/10.1016/ S0039-9140(02)00378-8

68. Gladis J, Rao J (2002) Quinoline-8-ol-immobilized Amberlite XAD-4: synthesis, characterization, and uranyl ion uptake properties suitable for analytical applications. Anal Bioanal Chem 373:867-887. https://doi.org/10.1007/s00216-002-1387-7.12194 052

69. Jain V, Handa A, Sait S et al (2001) Pre-concentration, separation and trace determination of lanthanum(III), cerium(III), thorium(IV) and uranium(VI) on polymer supported o-vanillinsemicarbazone. Anal Chim Acta 429:237-246. https://doi. org/10.1016/S0003-2670(00)01299-X

70. Kumar M, Rathore D, Singh A (2001) Pyrogallol immobilized Amberlite XAD-2: a newly designed collector for enrichment of metal ions prior to their de-termination by flame atomic absorption spectrometry. Mikrochim Acta 137:127-134. https ://doi.org/10.1007/s006040170002

71. Jal P, Dutta R, Sudershan K (2001) Extraction of metal ions using chemically modified silica gel: a PIXE analysis. Talanta 55:233240. https://doi.org/10.1016/S0039-9140(00)00678-0

72. Kumar M, Rathore D, Singh A (2000) Metal ion enrichment with Amberlite XAD-2 functionalized with Tiron: analytical applications. Analyst 125:1221-1226. https://doi.org/10.1039/b0008 $58 n$ 
73. Prabhakaran D, Subramanian M (2004) Selective extraction of $\mathrm{U}(\mathrm{VI}), \mathrm{Th}(\mathrm{IV})$, and $\mathrm{La}(\mathrm{III})$ from acidic matrix solutions and environmental samples using chemically modified Amberlite XAD-16 resin. Anal Bioanal Chem 379:519-525. https://doi.org/10.1007/ s00216-004-2600-7

74. Hosseini M, Hosseini M, Bandeh-Gharaei A (2007) Solvent impregnated resins containing quinizarin: preparation and application to batch-mode separation of $\mathrm{Cd}(\mathrm{II}), \mathrm{Cu}(\mathrm{II}), \mathrm{Ni}(\mathrm{II})$, and $\mathrm{Zn}$ (II) in aqueous media prior to the determination by flame atomic absorption spectrometry. Sep Sci Technol 42:3465-3480. https://doi.org/10.1080/01496390701626552

75. Ummathur M, Malini P, Krishnankutty K (2013) Dioxouranium(VI) complexes of some unsaturated $\beta$-diketones. Int J Chem Technol Res 5:1-5

76. Foo K, Hameed B (2010) Insights into the modeling of adsorption isotherm systems. Chem Eng J 156:2-10. https://doi. org/10.1016/j.cej.2009.09.013

77. Aksoyoglu S (1989) Sorption of U(VI) on granite. J Radioanal Nucl Chem 134:393-403

78. Chen A, Chen S (2009) Biosorption of azo dyes from aqueous solution by glutaraldehyde-crosslinked chitosans. J Hazard Mater 172:1111-1121

79. Kundu S, Gupta A (2006) Arsenic adsorption onto iron oxidecoated cement (IOCC): regression analysis of equilibrium data with several isotherm models and their optimization. Chem Eng J 122:93-106

80. Zhang X, Jiao C, Wang J et al (2012) Removal of uranium) VI) from aqueous solutions by magnetic schiff base: kinetic and thermodynamic investigation. Chem Eng J 198-199:412-419

81. Lima E, Hosseini-Bandegharaei A, Moreno-Piraján J et al (2019) A critical review of the estimation of the thermodynamic parameters on adsorption equilibria. Wrong use of equilibrium constant in the Van't Hoof equation for calculation of thermodynamic parameters of adsorption. J Mol Liq 273:425-434
82. Elsalamouny A, Desouky O, Mohamed S et al (2017) Evaluation of adsorption behavior for $\mathrm{U}(\mathrm{VI})$ and $\mathrm{Nd}(\mathrm{III})$ ions onto fumarated polystyrene microspheres. J Radioanal Nucl Chem 314:429-437. https://doi.org/10.1007/s10967-017-5389-5

83. Khawassek Y, Masoud A, Taha M et al (2018) Kinetics and thermodynamics of uranium ion adsorption from waste solution using Amberjet $1200 \mathrm{H}$ as cation exchanger. J Radioanal Nucl Chem 315:493-502. https://doi.org/10.1007/s10967-017-5692-1

84. Orabi A, Atrees M, Salem H (2018) Selective preconcentration of uranium on chitosan Steroyl thiourea prior to its spectrophotometric determination. Sep Sci Technol 53(14):2267-2283. https ://doi.org/10.1080/01496395.2018.1445113

85. Cheira M (2015) Synthesis of pyridylazo resorcinol-functionalized Amberlite XAD-16 and its characteristics for uranium recovery. J Environ Chem Eng 3:642-652. https://doi.org/10.1016/j. jece.2015.02.003

86. Afifi S, Mustafa M, El Sheikh E et al (2012) Extraction and determination of thorium and its application on geologic samples using trioctyl phosphine oxide. Arab J Nucl Sci Appl 45(3):1-16

87. Fouad H, Abu Elenein S, Elrakaiby R et al (2015) A developed spectrophotometric method for thorium determination using Alizarin Red S Dye in different types of its bearing rocks. Int J Sci Res 4:1611-1615

88. Bale M, Sawant A (2011) Solvent extraction and spectrophotometric determination of uranium( $\mathrm{VI}$ ) with pyridine- 2-carboxaldehyde 2-hydroxybenzoylhydrazone. J Radioanal Nucl Chem 247:531-534. https://doi.org/10.1023/A:1010626409358

Publisher's Note Springer Nature remains neutral with regard to jurisdictional claims in published maps and institutional affiliations. 